\title{
Mechanoelectric Feedback as a Trigger Mechanism for Cardiac Electrical Remodeling: A Model Study
}

\author{
Nico H. L. Kuijpers, ${ }^{1}$ Huub M. M. Ten Eikelder, ${ }^{2}$ Peter H. M. Bovendeerd, ${ }^{2}$ Sander Verheule, ${ }^{3}$ \\ Theo Arts, ${ }^{4}$ and Peter A. J. Hilbers ${ }^{2}$ \\ ${ }^{1}$ Department of Biomedical Engineering, Maastricht University, P.O. Box 616, 6200 MD Maastricht, The Netherlands; \\ ${ }^{2}$ Department of Biomedical Engineering, Eindhoven University of Technology, Eindhoven, The Netherlands; ${ }^{3}$ Department \\ of Physiology, Maastricht University, Maastricht, The Netherlands; and ${ }^{4}$ Department of Biophysics, Maastricht University, \\ Maastricht, The Netherlands
}

(Received 11 December 2007; accepted 27 August 2008; published online 6 September 2008)

\begin{abstract}
Regional variation in ionic membrane currents causes differences in action potential duration (APD) and is proarrhythmic. After several weeks of ventricular pacing, AP morphology and duration are changed due to electrical remodeling of the transient outward potassium current $\left(I_{\text {to }}\right)$ and the L-type calcium current $\left(I_{\mathrm{Ca}, \mathrm{L}}\right)$. It is not clear what mechanism drives electrical remodeling. By modeling the cardiac muscle as a string of segments that are electrically and mechanically coupled, we investigate the hypothesis that electrical remodeling is triggered by changes in mechanical load. Contractile force generated by the sarcomeres depends on the calcium transient and on the sarcomere length. Stroke work is determined for each segment by simulating the cardiac cycle. Electrical remodeling is simulated by adapting $I_{\mathrm{Ca}, \mathrm{L}}$ kinetics such that a homogeneous distribution of stroke work is obtained. With electrical remodeling, a more homogeneous shortening of the fiber is obtained, while heterogeneity in APD increases and the repolarization wave reverses. Our results are in agreement with experimentally observed homogeneity in mechanics and heterogeneity in electrophysiology. In conclusion, electrical remodeling is a possible mechanism to reduce heterogeneity in cardiomechanics induced by ventricular pacing.
\end{abstract}

Keywords-Cardiac memory, Electrical remodeling, Excitation-contraction coupling, Mechanoelectric feedback.

\section{INTRODUCTION}

Heterogeneity in action potential morphology and duration is an important factor in the initiation and persistence of reentrant arrhythmia such as atrial fibrillation (AF). ${ }^{2,6,59}$ An inverse relationship between action potential duration (APD) and activation time has been found both in the atria ${ }^{63,64,69}$ and in the

\footnotetext{
Address correspondence to Nico H. L. Kuijpers, Department of Biomedical Engineering, Maastricht University, P.O. Box 616, 6200 MD Maastricht, The Netherlands. Electronic mail: nico.kuijpers@ bf.unimaas.nl
}

ventricles. ${ }^{17}$ Differences in atrial action potential morphology are related to a regional variation in ionic membrane currents. ${ }^{15}$ In the ventricles, differences in ionic membrane currents between the left ventricle $(\mathrm{LV})$ and the right ventricle $(\mathrm{RV})^{68}$ and between the apex and base of the $\mathrm{LV}^{5}$ have been observed. Cordeiro et al. ${ }^{10}$ observed transmural heterogeneity in ionic currents, which was related to differences in mechanical function and is believed to help synchronize contraction in the ventricular wall.

Changing the activation sequence in the ventricles by pacing from a different site results in APD prolongation near the pacing site and APD shortening in remote regions. ${ }^{11,40}$ After several hours, these changes in electrophysiology lead to modulation of the $\mathrm{T}$ wave in the electrocardiogram (ECG). When normal activation is restored, the normal $\mathrm{T}$ wave reappears after several days. This phenomenon is known as "cardiac memory" and was first described by Rosenbaum et al. ${ }^{55}$ Herweg et al. ${ }^{20}$ observed changes in the atrial $\mathrm{T}$ wave (Ta wave) after changing the activation sequence in canine atria, indicating that cardiac memory is possible in the atria. In contrast, no evidence for "atrial memory" has been found in the goat. ${ }^{69}$

Experimental results indicate that both the transient outward potassium $\left(\mathrm{K}^{+}\right)$current $\left(I_{\mathrm{to}}\right)^{57}$ and the L-type calcium $\left(\mathrm{Ca}^{2+}\right)$ current $\left(I_{\mathrm{Ca}, \mathrm{L}}\right)^{7,49}$ are involved in electrical remodeling after changing the activation sequence in the ventricles. Yu et al. ${ }^{72}$ observed a reduction in $I_{\text {to }}$ current size, which explains disappearance of the notch in the AP after remodeling. Plotnikov et al. ${ }^{49}$ reversed the activation sequence in the canine heart from epicardium to endocardium by pacing the left ventricle. After 21 days, they isolated epicardial myocytes and compared $I_{\mathrm{Ca}, \mathrm{L}}$ current size and kinetics to $I_{\mathrm{Ca}, \mathrm{L}}$ in control (normally stimulated) epicardial myocytes. They found a similar $I_{\mathrm{Ca}, \mathrm{L}}$ current 
size, but observed a shift in activation towards a more positive membrane potential and slower inactivation after ventricular pacing. These changes in $I_{\mathrm{Ca}, \mathrm{L}}$ kinetics probably contribute to the increased APD and plateau height observed after pacing. ${ }^{49}$ After $2 \mathrm{~h}$ of pacing the canine left ventricle, Patberg et al. ${ }^{48}$ found a significant decrease in nuclear cAMP-responsive element binding protein (CREB) that did not occur in control dogs or in dogs treated with the $I_{\mathrm{Ca}, \mathrm{L}}$ blocker nifidipine. These observations indicate that changes in the $I_{\mathrm{Ca}, \mathrm{L}}$ current are related to modifications in the transcription of the $I_{\mathrm{Ca}, \mathrm{L}}$ channel. $^{7}$

At present, it is unclear what mechanism drives electrical remodeling after changing the activation sequence. Based on experimental observations, Jeyaraj et al $^{26}$ suggest mechanoelectric feedback as a mechanism for electrical remodeling. Recently, Sosunov et $a l .{ }^{62}$ found that electrical remodeling can be inhibited either by reducing mechanical load or by reducing contractility. These findings indicate that changes in mechanical load are involved in electrical remodeling after changing the activation sequence.

$\mathrm{Lab}^{36,37}$ reviewed several mechanisms for mechanoelectric feedback in the heart. These mechanisms include immediate influence on the action potential through stretch-activated channels (SACs), ${ }^{16,22,31}$ force-feedback on the intracellular $\mathrm{Ca}^{2+}$ concentration $\left(\left[\mathrm{Ca}^{2+}\right]_{\mathrm{i}}\right),{ }^{38}$ and long-term effects involving cell signaling pathways. ${ }^{58}$ Prinzen et al. ${ }^{50,51}$ and Delhaas et al. ${ }^{13}$ observed homogeneous strain and mechanical work when the heart was paced from the right atrium (normal stimulation). However, during ventricular pacing, systolic fiber strain and mechanical work were approximately zero near the stimulation site, and gradually increased to more than twice the normal value in remote regions. ${ }^{51}$ We hypothesize that the deviation from normal mechanical work observed after ventricular pacing functions as a trigger for electrical remodeling.

In the present study, we investigate the effect of changing maximum $I_{\text {to }}$ conductance, maximum $I_{\mathrm{Ca}, \mathrm{L}}$ conductance, and $I_{\mathrm{Ca}, \mathrm{L}}$ kinetics on AP morphology, $\mathrm{Ca}^{2+}$ dynamics, and mechanical behavior. To investigate the hypothesis that electrical remodeling is triggered by deviations from normal mechanical work, we apply our Cellular Bidomain Model, ${ }^{32,33}$ which has been extended with cardiomechanics. ${ }^{34,35}$ The model describes ionic membrane currents, storage and release of $\mathrm{Ca}^{2+}$ from the sarcoplasmic reticulum (SR), $\mathrm{Ca}^{2+}$ buffering, and cross-bridge formation. Contractile forces are coupled to $\left[\mathrm{Ca}^{2+}\right]_{i}$ and sarcomere length. With this model, ventricular electromechanics during the cardiac cycle is simulated in a cardiac fiber and stroke work is computed for each segment. Under the assumption that stroke work is homogeneously distributed after remodeling, we investigate the hypothesis that remodeling of $I_{\mathrm{Ca}, \mathrm{L}}$ is triggered by changes in mechanical load.

\section{METHODS}

To investigate the effect of remodeling of ionic currents on cardiac electrophysiology and mechanics, we apply our discrete bidomain model, the Cellular Bidomain Model. ${ }^{32,33}$ The model describes active membrane behavior as well as intracellular coupling and interstitial currents, and has been recently extended to describe cardiac mechanics. ${ }^{34,35}$ Here, we summarize our model of cardiac electrophysiology, the $\mathrm{Ca}^{2+}$-force relation, and the mechanical behavior of a cardiac fiber. Furthermore, we describe the simulation of a cardiac cycle, adaptation of $I_{\mathrm{to}}$ and $I_{\mathrm{Ca}, \mathrm{L}}$, and the numerical integration scheme. Finally, an overview is given of the simulations performed.

\section{Modeling Cardiac Electrophysiology}

In the Cellular Bidomain Model, a distinction is made between the intracellular domain and the interstitium. The tissue is subdivided in segments. The electrophysiological state of each segment is defined by the intracellular potential $\left(V_{\text {int }}\right)$, the extracellular potential $\left(V_{\text {ext }}\right)$, and the state of the cell membrane, which is expressed in gating variables and ion concentrations. The membrane potential $\left(V_{\mathrm{mem}}\right)$ is defined by

$$
V_{\mathrm{mem}}=V_{\mathrm{int}}-V_{\mathrm{ext}} \text {. }
$$

Exchange of current between the intracellular and extracellular domains occurs as transmembrane current $\left(I_{\text {trans }}\right)$, which depends on ionic current $\left(I_{\text {ion }}\right)$ and capacitive current according to

$$
I_{\text {trans }}=\chi\left(C_{\text {mem }} \frac{\mathrm{d} V_{\text {mem }}}{\mathrm{d} t}+I_{\text {ion }}\right),
$$

where $\chi$ is the ratio of membrane area to tissue volume and $C_{\mathrm{mem}}$ represents membrane capacitance per unit membrane surface. $I_{\text {trans }}$ is expressed per unit of tissue volume in $\mu \mathrm{A} \mathrm{cm}^{-3}$. Assuming $C_{\mathrm{mem}}=1 \mu \mathrm{F} \mathrm{cm}$, $I_{\text {ion }}$ is expressed in $\mathrm{pA} / \mathrm{pF}$ and depends on $V_{\mathrm{mem}}$, gating variables, and ion concentrations. To model $I_{\text {ion }}$, we apply the Courtemanche-Ramirez-Nattel model. ${ }^{12}$ The total ionic current is given by

$$
\begin{aligned}
I_{\text {ion }}= & I_{\mathrm{Na}}+I_{\mathrm{K} 1}+I_{\mathrm{to}}+I_{\mathrm{Kur}}+I_{\mathrm{Kr}}+I_{\mathrm{Ks}}+I_{\mathrm{Ca}, \mathrm{L}}+I_{\mathrm{p}, \mathrm{Ca}} \\
& +I_{\mathrm{NaK}}+I_{\mathrm{NaCa}}+I_{\mathrm{b}, \mathrm{Na}}+I_{\mathrm{b}, \mathrm{Ca}},
\end{aligned}
$$

where $I_{\mathrm{Na}}$ is fast inward $\mathrm{Na}^{+}$current, $I_{\mathrm{K} 1}$ is inward rectifier $\mathrm{K}^{+}$current, $I_{\text {to }}$ is transient outward $\mathrm{K}^{+}$ current, $I_{\mathrm{Kur}}$ is ultrarapid delayed rectifier $\mathrm{K}^{+}$current, 
$I_{\mathrm{Kr}}$ is rapid delayed rectifier $\mathrm{K}^{+}$current, $I_{\mathrm{Ks}}$ is slow delayed rectifier $\mathrm{K}^{+}$current, $I_{\mathrm{Ca}, \mathrm{L}}$ is L-type $\mathrm{Ca}^{2+}$ current, $I_{\mathrm{p}, \mathrm{Ca}}$ is $\mathrm{Ca}^{2+}$ pump current, $I_{\mathrm{NaK}}$ is $\mathrm{Na}^{+}-\mathrm{K}^{+}$ pump current, $I_{\mathrm{NaCa}}$ is $\mathrm{Na}^{+} / \mathrm{Ca}^{2+}$ exchanger current, and $I_{\mathrm{b}, \mathrm{Na}}$ and $I_{\mathrm{b}, \mathrm{Ca}}$ are background $\mathrm{Na}^{+}$and $\mathrm{Ca}^{2+}$ currents. ${ }^{12} \mathrm{Ca}^{2+}$ handling by the sarcoplasmic reticulum (SR) is described by considering three compartments: myoplasm, SR release compartment (junctional SR), and SR uptake compartment (network SR). The model also describes $\mathrm{Ca}^{2+}$ buffering within the cytoplasm mediated by troponin and by calmodulin as well as $\mathrm{Ca}^{2+}$ buffering within the release compartment mediated by calsequestrin. ${ }^{12}$

Intracellular and extracellular currents between adjacent segments are related to intracellular and extracellular conductivities ( $g_{\text {int }}$ and $g_{\text {ext }}$ ) and satisfy Ohm's law. Conductivities are adjusted for changing stretch ratio as described previously. ${ }^{35}$ The bidomain parameters used for the present study are from Henriquez $^{19}$ and are based on measurements by Clerc ${ }^{9}$ (Table 1).

\section{Mechanical Behavior of a Cardiac Fiber}

The mechanical behavior of a single segment is modeled as described previously ${ }^{35}$ by the classical three-element rheological scheme introduced by Hill in $1938 .^{21}$ The model is formulated in terms of tension (first Piola Kirchhoff stress), defined as force per unit of fiber cross-sectional area in the undeformed state. Active tension is generated by the contractile element (CE) together with the series elastic element (SE) and passive tension is generated in the parallel elastic element (PE). The PE describes the tension-length relationship when the segment is not stimulated. Contractile tension $\left(T_{\mathrm{CE}}\right)$ generated by the $\mathrm{CE}$ depends on $\left[\mathrm{Ca}^{2+}\right]_{i}$, the length of the $\mathrm{CE}\left(l_{\mathrm{CE}}\right)$, and the velocity of sarcomere shortening $v=-\frac{\mathrm{d} l_{\mathrm{CE}}}{\mathrm{d} t} \cdot T_{\mathrm{CE}}$ is defined by

$$
T_{\mathrm{CE}}=f_{\mathrm{CE}} f_{v}(v) F_{\text {norm }}\left(\left[\mathrm{Ca}^{2+}\right]_{\mathrm{i}}, l_{\mathrm{CE}}\right),
$$

where $f_{\mathrm{CE}}$ is a scaling factor, $f_{v}(v)$ is Hill's forcevelocity relation, and $F_{\text {norm }}\left(\left[\mathrm{Ca}^{2+}\right]_{\mathrm{i}}, l_{\mathrm{CE}}\right)$ is the normalized force generated by the sarcomeres. We model the Hill relation by a hyperbolic function as proposed by Hunter et al. ${ }^{23}$ Function $f_{v}(v)$ is defined by

$$
f_{v}(v)=\frac{1-\frac{v}{v_{\max }}}{1+c_{v} \frac{v}{v_{\max }}},
$$

where $v_{\max }$ is the maximum velocity of sarcomere shortening and $c_{v}$ is a constant describing the shape of the hyperbolic relationship ${ }^{35}$ (Table 1).

$F_{\text {norm }}\left(\left[\mathrm{Ca}^{2+}\right]_{\mathrm{i}}, l_{\mathrm{CE}}\right)$ is modeled by model 4 from Rice et al.,${ }^{54}$ which is based on a functional unit of troponin, tropomyosin, and actin. In our model, binding of $\mathrm{Ca}^{2+}$ to troponin is modeled in two different ways: the $\mathrm{Ca}^{2+}$ transient is computed by the model of Courtemanche et al. ${ }^{12}$ using a steady-state formulation for $\mathrm{Ca}^{2+}$-troponin binding; $F_{\text {norm }}$ is computed by the model of Rice et al. ${ }^{54}$ using differential equations for the $\mathrm{Ca}^{2+}$-troponin binding and $\left[\mathrm{Ca}^{2+}\right]_{\mathrm{i}}$ obtained from the model of Courtemanche et al. ${ }^{12}$ (see Kuijpers et $a l .{ }^{35}$ for more detail). In the model of Rice et al. ${ }^{54}$ troponin can be in one of two states, indicating whether it is unbound or bound to $\mathrm{Ca}^{2+}$. Tropomyosin can be in one of six states of which two represent the non-permissive states with 0 and 1 cross bridges, and the other four the permissive states with $0,1,2$, and 3 cross bridges. ${ }^{54}$ Transitions between the states are governed by rate functions that depend on $\left[\mathrm{Ca}^{2+}\right]_{\mathrm{i}}$ and $l_{\mathrm{CE}}$. The force generated by the sarcomeres depends on

TABLE 1. Model parameters.

\begin{tabular}{lll}
\hline Parameter & \multicolumn{1}{c}{ Definition } & \multicolumn{1}{c}{ Value } \\
\hline$g_{\mathrm{int}}^{\mathrm{A}}$ & Longitudinal intracellular conductivity (Fiber A) & $5.2266 \mathrm{mS} \mathrm{cm}^{-1}$ \\
$g_{\mathrm{ext}}^{\mathrm{A}}$ & Longitudinal extracellular conductivity (Fiber A) & $18.7500 \mathrm{mS} \mathrm{cm}^{-1}$ \\
$g_{\mathrm{int}}^{\mathrm{B}}$ & Longitudinal intracellular conductivity (Fiber B) & $1.7422 \mathrm{mS} \mathrm{cm}^{-1}$ \\
$g_{\mathrm{ext}}^{\mathrm{B}}$ & Longitudinal extracellular conductivity (Fiber B) & $6.2500 \mathrm{mS} \mathrm{cm}^{-1}$ \\
$g_{\mathrm{int}}^{\mathrm{C}}$ & Longitudinal intracellular conductivity (Fiber C) & $0.5802 \mathrm{mS} \mathrm{cm}^{-1}$ \\
$g_{\mathrm{ext}}^{\mathrm{C}}$ & Longitudinal extracellular conductivity (Fiber C) & $2.0813 \mathrm{mS} \mathrm{cm}^{-1}$ \\
$C_{\mathrm{mem}}$ & Membrane capacitance per unit membrane surface & $1.0 \mu \mathrm{Fm}^{-2}$ \\
$\chi$ & Surface-to-volume ratio & $2000 \mathrm{~cm}^{-1}$ \\
$f_{\mathrm{CE}}$ & Scaling factor for contractile element & $100 \mathrm{kPa}$ \\
$l_{\mathrm{CEO}}$ & Reference length of contractile element & $1.78 \mu \mathrm{m}$ \\
$v_{\mathrm{max}}$ & Maximum velocity of sarcomere shortening & $0.0055 \mu \mathrm{m} \mathrm{ms}$ \\
$c_{V}$ & Constant describing the hyperbolic shape of the Hill relation & 2 \\
$f_{\mathrm{SE}}$ & Scaling factor for series elastic element & $28 \mathrm{kPa}$ \\
$k_{\mathrm{SE}}$ & Material constant for series elastic element & $14.6 \mu \mathrm{m}^{-1}$ \\
$f_{\mathrm{PE}}$ & Scaling factor for parallel elastic element & $0.006 \mathrm{kPa}$ \\
$k_{\mathrm{PE}}$ & Material constant for parallel elastic element & $14.6 \mu \mathrm{m}^{-1}$ \\
$l_{\mathrm{PEO}}$ & Reference length of parallel elastic element & $1.78 \mu \mathrm{m}$ \\
\hline
\end{tabular}


the fraction of tropomyosin in the states that represent cross-bridge formation. We do not consider a direct feedback mechanism that influences the $\mathrm{Ca}^{2+}$ transient through a change in the affinity of troponin for $\mathrm{Ca}^{2+}$ binding as in model 5 of Rice et al. ${ }^{53,54}$ The reader is referred to Rice et al. ${ }^{54}$ or Kuijpers et al. ${ }^{35}$ for a graphical representation of the steady-state $\mathrm{Ca}^{2+}$ force relation.

Tensions generated in the $\mathrm{SE}$ and in the $\mathrm{PE}\left(T_{\mathrm{SE}}\right.$ and $\left.T_{\mathrm{PE}}\right)$ are exponentially related to the length of the SE $\left(l_{\mathrm{SE}}\right)$ and the sarcomere length $\left(l_{\mathrm{PE}}\right)$, and are defined by

$$
T_{\mathrm{SE}}=f_{\mathrm{SE}}\left(\exp \left(k_{\mathrm{SE}} l_{\mathrm{SE}}\right)-1\right)
$$

and

$$
T_{\mathrm{PE}}=f_{\mathrm{PE}}\left(\exp \left(k_{\mathrm{PE}}\left(l_{\mathrm{PE}}-l_{\mathrm{PE} 0}\right)\right)-1\right),
$$

where $f_{\mathrm{SE}}, k_{\mathrm{SE}}, f_{\mathrm{PE}}$, and $k_{\mathrm{PE}}$ are material constants describing the elasticity of the elements, and $l_{\mathrm{PE} 0}$ is the reference sarcomere length at which $T_{\mathrm{PE}}=0 \mathrm{kPa}$. Total tension generated by the segment $\left(T_{\text {segment }}\right)$ is the sum of passive tension $\left(T_{\mathrm{PE}}\right)$ and active tension $\left(T_{\mathrm{SE}}\right)$. In summary, it holds for the three-element model:

$$
\begin{gathered}
T_{\mathrm{CE}}=T_{\mathrm{SE}}, \\
T_{\text {segment }}=T_{\mathrm{SE}}+T_{\mathrm{PE}}, \\
l_{\mathrm{PE}}=l_{\mathrm{CE}}+l_{\mathrm{SE}} .
\end{gathered}
$$

Most parameters for the three-element mechanical model are from Solovyova et al. ${ }^{61}$ and Kuijpers et al. ${ }^{35}$ (Table 1). Parameter $f_{\mathrm{SE}}$ is changed from $2.8 \mathrm{kPa}$ in Kuijpers et al. ${ }^{35}$ to $28 \mathrm{kPa}$ to account for the experimentally observed fiber shortening of $1 \%$ in a quickrelease experiment. ${ }^{14,23}$ With these parameters, both the active and the passive tension-sarcomere length relation are in agreement with experimental data measured by Kentish et al. ${ }^{28}$ The reader is referred to Kuijpers et al. $^{35}$ for a graphical representation of active and passive tension-sarcomere length relations in our model.

\section{Cardiac Cycle Simulation}

The myofibers in the heart are represented by a single string of segments that are coupled in series. In the undeformed state, all segments have the same length $(0.1 \mathrm{~mm})$ and cross-sectional area $\left(0.01 \mathrm{~mm}^{2}\right){ }^{35}$ The stretch ratio of a single segment ( $\left.\lambda_{\text {segment }}\right)$ is defined by

$$
\lambda_{\text {segment }}=\frac{l_{\mathrm{PE}}}{l_{\mathrm{PE} 0}},
$$

and the stretch ratio of the fiber $\left(\lambda_{\text {fiber }}\right)$ is defined as the average stretch ratio of the segments. From mechanical equilibrium, it follows that the tension generated by each segment, $T_{\text {segment, }}$ must be equal to the tension applied to the fiber, $T_{\text {fiber }}$.

To simulate the cardiac cycle, we extend the preload-afterload experiment as described by Brutsaert and Sonnenblick. ${ }^{8}$ We distinguish five phases as follows (Fig. 1):

1. Filling: linear increase during $300 \mathrm{~ms}$ of the load from $T_{\text {fiber }}=T_{\text {rest }}$ till $T_{\text {fiber }}=T_{\text {preload }}$;

2. Isovolumic contraction: isometric simulation (constant $\lambda_{\text {fiber }}$ ) until $T_{\text {fiber }}=T_{\text {afterload; }}$

3. Ejection: isotonic simulation (constant $\left.T_{\text {fiber }}=T_{\text {afterload }}\right)$ until $\lambda_{\text {fiber }}$ stops decreasing;

4. Isovolumic relaxation: isometric simulation (constant $\lambda_{\text {fiber }}$ ) until $T_{\text {fiber }}=T_{\text {rest }}$;

5. Isotonic relaxation: isotonic simulation (constant $\left.T_{\text {fiber }}=T_{\text {rest }}\right)$ until filling starts.

During filling, ejection, and isotonic relaxation, the load applied to the cardiac fiber $\left(T_{\text {fiber }}\right)$ is set as a boundary condition, whereas during isovolumic contraction and isovolumic relaxation, the stretch ratio of the fiber $\left(\lambda_{\text {fiber }}\right)$ is a boundary condition. To initiate contraction, the first segment is electrically stimulated at the beginning of isovolumic contraction.

In Fig. 1, a stress-strain loop is presented. The five phases of the cardiac cycle are indicated by the

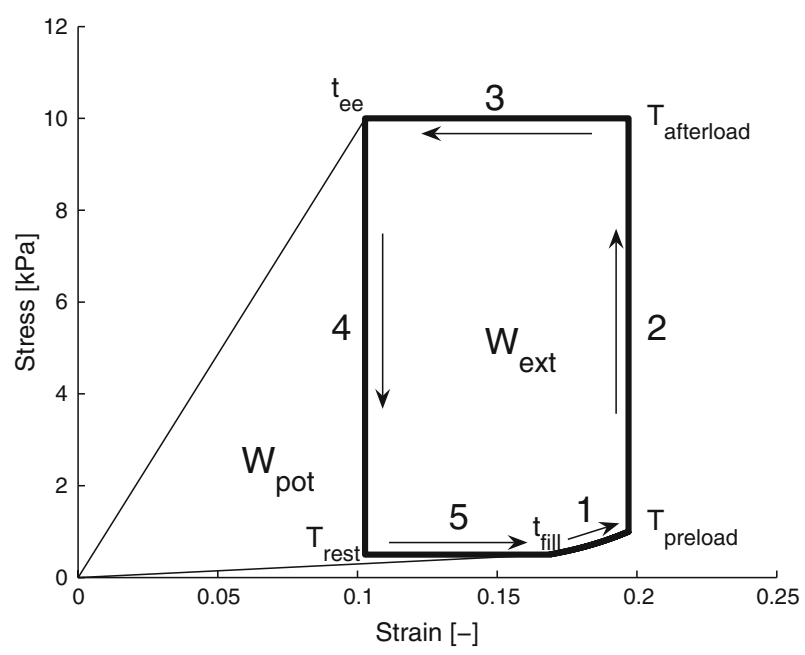

FIGURE 1. Overview of the preload-afterload experiment simulating the cardiac cycle. The five phases of the cardiac cycle are indicated by numbers as follows: 1 , filling; 2 , isovolumic contraction; 3 , ejection; 4 , isovolumic relaxation; and 5 , isotonic relaxation. The arrows indicate the direction of time; $t_{\text {fill }}$ indicates the time at which filling starts and $t_{\mathrm{ee}}$ the time at end of ejection. A cardiac cycle was simulated with $T_{\text {rest }}=0.5 \mathrm{kPa}, T_{\text {preload }}=1 \mathrm{kPa}$, and $T_{\text {afterload }}=10 \mathrm{kPa}$. Strain is defined as $\lambda-1$, where $\lambda$ is the stretch ratio. External stroke work density $\left(W_{\text {ext }}\right)$ is the area indicated by $W_{\text {ext }}$ and potential work density $\left(W_{\text {pot }}\right)$ is the area indicated by $W_{\text {pot- }}$ Total stroke work density $\left(W_{\text {tot }}\right)$ is the sum of $W_{\text {ext }}$ and $W_{\text {pot- }}$ 
numbers 1 through 5 , and the direction of time is indicated by arrows. A cardiac cycle was simulated with $T_{\text {rest }}=0.5 \mathrm{kPa}, T_{\text {preload }}=1 \mathrm{kPa}$, and $T_{\text {afterload }}=$ $10 \mathrm{kPa}$. These values are in agreement with the experiments by Iribe et $\mathrm{al}^{24}$

\section{Adaptation of $I_{t o}$ and $I_{C a, L}$}

To investigate the effect of changes in $I_{\mathrm{to}}$ and $I_{\mathrm{Ca}, \mathrm{L}}$ in relation to the calcium transient and cardiomechanics, we vary the maximum conductance of $I_{\text {to }}$ and $I_{\mathrm{Ca}, \mathrm{L}}$. Furthermore, we model the changes in $I_{\mathrm{Ca}, \mathrm{L}}$ kinetics as observed by Plotnikov et al ${ }^{49}$ after ventricular pacing.

In the Courtemanche-Ramirez-Nattel model, $I_{\text {to }}$ is defined by

$$
I_{\mathrm{to}}=g_{\mathrm{to}} o_{\mathrm{a}}^{3} o_{\mathrm{i}}\left(V_{\mathrm{mem}}-E_{\mathrm{K}}\right),
$$

where $g_{\text {to }}$ is the maximum $I_{\text {to }}$ conductance, $o_{\mathrm{a}}$ and $o_{\mathrm{i}}$ are the activation and inactivation gating variables, and $E_{\mathrm{K}}$ is the equilibrium potential for $\mathrm{K}^{+} .^{12} I_{\mathrm{Ca}, \mathrm{L}}$ is defined by

$$
I_{\mathrm{Ca}, \mathrm{L}}=g_{\mathrm{Ca}, \mathrm{L}} d f f_{\mathrm{Ca}}\left(V_{\mathrm{mem}}-65\right),
$$

where $g_{\mathrm{Ca}, \mathrm{L}}$ is the maximum $I_{\mathrm{Ca}, \mathrm{L}}$ conductance, $d$ is the activation gating variable, $f$ is the voltage-dependent inactivation gating variable, and $f_{\mathrm{Ca}}$ is the $\mathrm{Ca}^{2+}$ dependent inactivation gating variable. ${ }^{12}$ Changing the $I_{\mathrm{to}}$ and $I_{\mathrm{Ca}, \mathrm{L}}$ current size is realized by changing $g_{\mathrm{to}}$ and $g_{\mathrm{Ca}, \mathrm{L}}$, respectively.

Plotnikov et al. ${ }^{49}$ observed a more positive activation and slower inactivation of $I_{\mathrm{Ca}, \mathrm{L}}$ in patch-clamp experiments. To account for the shift in $I_{\mathrm{Ca}, \mathrm{L}}$ activation, $I_{\mathrm{Ca}, \mathrm{L}}$ kinetics are changed by adaption of the dynamics of activation gating variable $d$. In the Courtemanche-Ramirez-Nattel model, the dynamics of $d$ are defined by

$$
\frac{\mathrm{d}}{\mathrm{d} t} d=\frac{d_{\infty}-d}{\tau_{d}},
$$

where steady-state value $d_{\infty}$ and time constant $\tau_{d}$ are defined by

$$
d_{\infty}=\frac{1}{1+\exp \left(-\frac{V_{\text {mem }}+V_{\text {shift }}}{8.0}\right)}
$$

and

$$
\tau_{d}=\frac{1-\exp \left(-\frac{V_{\text {mem }}+V_{\text {shitt }}}{6.24}\right)}{0.035\left(V_{\text {mem }}+V_{\text {shift }}\right)\left(1+\exp \left(-\frac{V_{\text {mem }}+V_{\text {shift }}}{6.24}\right)\right)},
$$

where $V_{\text {shift }}=10 \mathrm{mV}$.

We simulate remodeling of $I_{\mathrm{Ca}, \mathrm{L}}$ kinetics by replacing $V_{\text {shift }}$ in (15) and (16) with

$$
V_{\text {shift }}=V_{\text {shift,ref }}(\rho+1),
$$

where $V_{\text {shift,ref }}=10 \mathrm{mV}$ and $\rho$ is the remodeling parameter. Plotnikov et al. ${ }^{49}$ observed a shift of $10 \mathrm{mV}$ in $I_{\mathrm{Ca}, \mathrm{L}}$ activation in epicardial myocytes. Assuming a maximum shift of $10 \mathrm{mV}$, parameter $\rho$ ranges between -1.0 and 1.0 , where $\rho=0.0$ represents the reference situation.

\section{Mechanically Induced Remodeling of $I_{C a, L}$}

Based on the assumption that electrical remodeling is triggered by changes in mechanical load, we use stroke work per unit of tissue volume as a feedback signal to determine the remodeling parameter $\rho$. We distinguish between external stroke work density $\left(W_{\text {ext }}\right)$ and total stroke work density $\left(W_{\text {tot }}\right) . W_{\text {ext }}$ is defined as the area enclosed by the stress-strain loop during the cardiac cycle (Fig. 1):

$$
W_{\mathrm{ext}}=-\int_{0}^{t_{\mathrm{cycle}}} T(t) \mathrm{d} \epsilon(t),
$$

where $t_{\text {cycle }}$ is the duration of one cardiac cycle $(1 \mathrm{~s})$, $T(t)$ represents $T_{\text {segment }}$ at time $t$, and $\epsilon(t)$ the strain defined by $\epsilon=\lambda_{\text {segment }}-1$. $W_{\text {tot }}$ is the sum of $W_{\text {ext }}$ and the so-called potential work density $\left(W_{\text {pot }}\right)$, and is also referred to as the stress-strain area (SSA). ${ }^{13,65} W_{\text {tot }}$ is computed as

$$
W_{\text {tot }}=-\frac{T_{\text {rest }} \epsilon\left(t_{\text {fill }}\right)}{2}-\int_{t_{\text {fill }}}^{t_{\text {ee }}} T(t) \mathrm{d} \epsilon(t)+\frac{T_{\text {afterload }} \epsilon\left(t_{\text {ee }}\right)}{2},
$$

where $t_{\text {fill }}$ denotes the time at which filling starts and $t_{\mathrm{ee}}$ the time at end of ejection (Fig. 1).

For each segment $n$, the remodeling parameter is denoted by $\rho_{n}$. The parameters $\rho_{n}$ are determined such that stroke work is homogeneously distributed over the fiber. The $\rho_{n}$ are found by iteratively computing stroke work for each segment followed by adapting the $\rho_{n}$ until the $\rho_{n}$ no longer change. Stroke work generated by the segment in the center of the fiber is used as reference. This implicates that, although stroke work may change, the electrophysiology is not changed for the center segment. Initially, $\rho_{n}=0.0$ for each segment $n$. Each time a new cardiac cycle starts, $\rho_{n}$ is adapted by

$$
\rho_{n} \rightarrow \begin{cases}\rho_{n}+0.01 & \text { if } W_{n}<0.99 \cdot W_{\text {ref }} \text { and } \rho_{n}<1.0 \\ \rho_{n}-0.01 & \text { if } W_{n}>1.01 \cdot W_{\text {ref }} \text { and } \rho_{n}>-1.0 \\ \rho_{n} & \text { otherwise }\end{cases}
$$

Here, $W_{n}$ represents either $W_{\text {ext }}$ or $W_{\text {tot }}$ of segment $n$, and $W_{\text {ref }}$ represents either $W_{\text {ext }}$ or $W_{\text {tot }}$ of the reference segment. 


\section{Numerical Integration Scheme}

The Cellular Bidomain Model can be written as a coupled system of differential equations and linear equations. ${ }^{33}$ To obtain criteria for the size of the segments, we apply cable theory and consider subthreshold behavior along a fiber as previously described. ${ }^{33}$ For the bidomain parameters in Table 1, we obtain a length constant between $0.07 \mathrm{~cm}$ (Fiber C) and $0.21 \mathrm{~cm}$ (Fiber A), indicating that accurate results can be obtained with segments of length $0.01 \mathrm{~cm}$.

To compute $V_{\text {mem }}$, the differential equations are solved using a forward Euler scheme. The system of linear equation is solved each time step by an iterative method as described in Kuijpers et al. ${ }^{33}$ Since we use an explicit forward Euler scheme, the time step $(\Delta t)$ must satisfy the stability condition as formulated by Puwal and Roth. ${ }^{52}$ For a one-dimensional fiber this leads to

$$
\Delta t<\frac{\chi C_{\mathrm{mem}}\left(g_{\mathrm{int}}+g_{\mathrm{ext}}\right)}{2 g_{\mathrm{int}} g_{\mathrm{ext}}} \Delta x^{2},
$$

where $\Delta x$ is the segment size $(0.01 \mathrm{~cm})$. For the bidomain parameters defined in Table 1, we obtain $\Delta t<$ $0.024 \mathrm{~ms}$ for Fiber A, $\Delta t<0.073 \mathrm{~ms}$ for Fiber B, and $\Delta t<0.22 \mathrm{~ms}$ for Fiber C. By using $\Delta t=0.01 \mathrm{~ms}$, the stability condition is satisfied for each of the fibers.

The ionic currents are computed as described in Courtemanche et al. ${ }^{12}$ Computation time is reduced by increasing the simulation time step for the ionic currents to $0.1 \mathrm{~ms}$ during repolarization and rest. This leads to a reduction of $70 \%$ in computation time, without significant loss of accuracy. Both the $\mathrm{Ca}^{2+}$ force relation and cardiomechanics are computed using a forward Euler method with a time step of $0.01 \mathrm{~ms}$. Depending on the phase in the cardiac cycle, either $T_{\text {fiber }}$ or $\lambda_{\text {fiber }}$ is set as a boundary condition. The mechanical state of each segment is computed from the state obtained during the previous time step and the boundary condition. A numerical scheme that accounts for both boundary conditions is derived in Kuijpers et al. ${ }^{35}$ Initially, $T_{\text {fiber }}=0.0 \mathrm{kPa}$ and $\lambda_{\text {fiber }}=$ 1.0. During the first $200 \mathrm{~ms}, T_{\text {fiber }}$ is increased until $T_{\text {fiber }}=T_{\text {rest }}$. The first cardiac cycle starts after $1 \mathrm{~s}$.

\section{Simulation Protocol}

To investigate the effect of changing maximum $I_{\text {to }}$ conductance, maximum $I_{\mathrm{Ca}, \mathrm{L}}$ conductance, and $I_{\mathrm{Ca}, \mathrm{L}}$ kinetics on the action potential, calcium transient, and contractile force, a series of single-segment simulations was performed in which $g_{\mathrm{to}}, g_{\mathrm{Ca}, \mathrm{L}}$, and $\rho$ were varied. The segment was stimulated with a stimulation rate of $1 \mathrm{~Hz}$ using a stimulus current of $20 \mathrm{pA} / \mathrm{pF}$ during $2 \mathrm{~ms}$ as in Courtemanche et al. ${ }^{12}$ During the simulations,
$l_{\mathrm{CE}}$ was kept constant (isosarcometric contraction). In another series of simulations, the effect of changing preload and afterload was investigated by singlesegment simulations with $\rho=0.0, \rho=0.5$, and $\rho=1.0$. In these simulations, $T_{\text {rest }}=0.5 \mathrm{kPa}, T_{\text {preload }}$ ranged between 0.75 and $2.5 \mathrm{kPa}$, and $T_{\text {afterload }}$ ranged between 5 and $20 \mathrm{kPa}$.

Electrical remodeling was simulated using cardiac fibers with a reference length $\left(L_{0}\right)$ of $3 \mathrm{~cm}$. We distinguish three fibers with different conductivity properties (Table 1). Normal activation during sinus rhythm is represented by Fiber A, whereas an increased duration of complete activation with epicardial pacing is represented by the Fibers $B$ and $C$. With stimulation rate $1 \mathrm{~Hz}$, a depolarization wave was generated by stimulating the first segment using a stimulus current of $100 \mathrm{pA} / \mathrm{pF}$ until the membrane was depolarized. Depolarization of the entire fiber took $53 \mathrm{~ms}$ for Fiber A (conduction velocity $\theta=0.56 \mathrm{~m} \mathrm{~s}^{-1}$ ), $98 \mathrm{~ms}$ for Fiber $\mathrm{B}\left(\theta=0.31 \mathrm{~m} \mathrm{~s}^{-1}\right)$, and $191 \mathrm{~ms}$ for Fiber $\mathrm{C}$ $\left(\theta=0.16 \mathrm{~m} \mathrm{~s}^{-1}\right)$. Fiber A represents normal ventricular depolarization and Fiber B represents ventricular depolarization after epicardial pacing. Fiber $\mathrm{C}$ is included to compare our simulation results with the experimental results of Jeyaraj et al., ${ }^{26}$ who report a dispersion in depolarization time of $180 \mathrm{~ms}$. In all cases, the cardiac cycle was simulated with $T_{\text {rest }}=0.5 \mathrm{kPa}$, $T_{\text {preload }}=1 \mathrm{kPa}$, and $T_{\text {afterload }}=10 \mathrm{kPa}$.

To maintain steady-state, $\rho_{n}$ can decrease or increase at most 0.01 each cardiac cycle. Thus, it takes at least 100 cardiac cycles to reach $\rho_{n}=1.0$ or $\rho_{n}=-1.0$ for an individual segment $n$. In all cases, a final distribution of the $\rho_{n}$ was reached in at most 140 cardiac cycles. By simulating 150 cardiac cycles, it was ensured that steady-state was reached. Since the effect of the stimulus current and the intracellular currents on the intracellular concentrations of $\mathrm{Na}^{+}$and $\mathrm{K}^{+}\left(\left[\mathrm{Na}^{+}\right]_{\mathrm{i}}\right.$ and $\left[\mathrm{K}^{+}\right]_{\mathrm{i}}$ ) are not taken into account, a drift in the ionic balance between $\left[\mathrm{Na}^{+}\right]_{\mathrm{i}}$ and $\left[\mathrm{K}^{+}\right]_{\mathrm{i}}$ may occur during longer simulation runs. ${ }^{12,33}$ To avoid such drift, $\left[\mathrm{Na}^{+}\right]_{\mathrm{i}}$ and $\left[\mathrm{K}^{+}\right]_{\mathrm{i}}$ were kept constant during the entire simulation. By performing single-cell simulations with and without fixed $\left[\mathrm{Na}^{+}\right]_{\mathrm{i}}$ and $\left[\mathrm{K}^{+}\right]_{\mathrm{i}}$, we found that the effect of assuming constant $\left[\mathrm{Na}^{+}\right]_{\mathrm{i}}$ and $\left[\mathrm{K}^{+}\right]_{\mathrm{i}}$ on the AP morphology, $\mathrm{Ca}^{2+}$ transient, and ionic currents is marginal and can be neglected.

\section{RESULTS}

\section{Isosarcometric Contraction}

In Fig. 2, the effect of parameter $\rho$ on electrophysiology and $F_{\text {norm }}$ is compared with the effect of scaling $g_{\text {to }}$ and $g_{\mathrm{Ca}, \mathrm{L}}$ with a factor $0.3-1.7$. Increasing $g_{\text {to }}$ 

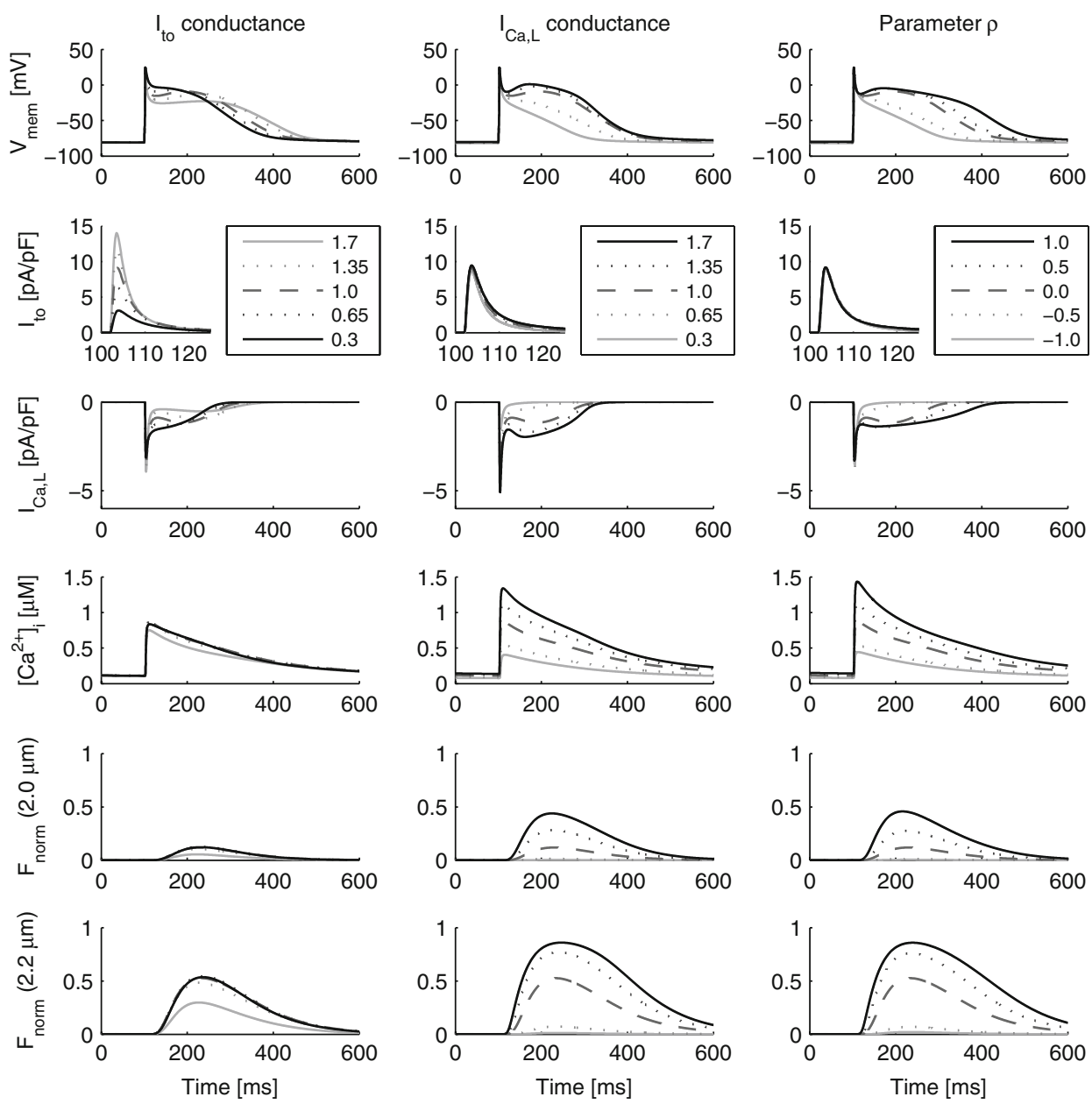

FIGURE 2. Comparison of scaling maximum $I_{\text {to }}$ conductance $\left(g_{\mathrm{to}}\right.$, factor $\left.0.3-1.7\right)$ and maximum $I_{\mathrm{Ca}, \mathrm{L}}$ conductance $\left(g_{\mathrm{Ca}, \mathrm{L}}\right.$, factor 0.3-1.7) with parameter $\rho$. From top to bottom: membrane potential $\left(V_{\text {mem }}\right)$, transient outward $\mathrm{K}^{+}$current $\left(I_{\text {to }}\right)$, L-type Ca ${ }^{2+}$ current $\left(I_{\mathrm{Ca}, \mathrm{L}}\right)$, intracellular $\mathrm{Ca}^{2+}$ concentration $\left(\left[\mathrm{Ca}^{2+}\right]_{\mathrm{i}}\right)$, normalized contractile force $\left(F_{\text {norm }}\right)$ for $I_{\mathrm{CE}}=2.0 \mu \mathrm{m}$, and $F_{\text {norm }}$ for $I_{\mathrm{CE}}=2.2 \mu \mathrm{m}$. A stimulus current was applied at 100 ms. Note the different time scale for $I_{\text {to. }}$.

results in a lower plateau phase, a prolonged APD, a reduced $\mathrm{Ca}^{2+}$ transient, and a lower $F_{\text {norm }}$. Decreasing $g_{\text {to }}$ leads to disappearance of the notch and a shorter APD, but has no significant influence on the $\mathrm{Ca}^{2+}$ transient and $F_{\text {norm }}$ (Fig. 2, left). Increasing $g_{\mathrm{Ca}, \mathrm{L}}$ does not affect the APD, but results in an increased $\mathrm{Ca}^{2+}$ transient and $F_{\text {norm }}$. Decreasing $g_{\mathrm{Ca}, \mathrm{L}}$ leads to a shorter APD, a reduced $\mathrm{Ca}^{2+}$ transient, and a lower $F_{\text {norm }}$ (Fig. 2, center). Interestingly, increasing $g_{\text {to }}$ with a factor larger than 2.5 also leads to a shorter APD and a reduced $\mathrm{Ca}^{2+}$ transient (results not shown). In that case, peak $I_{\text {to }}$ exceeds $14 \mathrm{pA} / \mathrm{pF}$, which results in early deactivation of $I_{\mathrm{Ca}, \mathrm{L}}$. Similar observations have been reported by Greenstein et al. ${ }^{18}$ with models of ventricular membrane behavior.

Parameter $\rho$ and scaling $g_{\mathrm{Ca}, \mathrm{L}}$ have similar effects on the $\mathrm{Ca}^{2+}$ transient and $F_{\text {norm }}$ (Fig. 2, center and right). In contrast with increasing $g_{\mathrm{Ca}, \mathrm{L}}$, increasing parameter $\rho$ results in a slower decrease of $I_{\mathrm{Ca}, \mathrm{L}}$ during the plateau phase and an increased APD, which is in agreement with the measurements by Plotnikov et al. ${ }^{49}$ Peak $\left[\mathrm{Ca}^{2+}\right]_{\mathrm{i}}$ increases for positive $\rho$ and decreases for negative $\rho$. Larger peak $\left[\mathrm{Ca}^{2+}\right]_{\mathrm{i}}$ corresponds to larger and more prolonged contractions. The traces of $F_{\text {norm }}$ are in agreement with experimental data obtained by Janssen and Hunter ${ }^{25}$ (see also Kuijpers et al. ${ }^{35}$ ).

In experiments, disappearance of the notch in epicardial cells was observed with epicardial pacing, which was related to a reduction in $I_{\mathrm{to}} \cdot{ }^{41,42,72}$ Since reducing $g_{\text {to }}$ has no significant influence on the $\mathrm{Ca}^{2+}$ transient and on $F_{\text {norm }}$ in our model, scaling $g_{\text {to }}$ is not further considered in the present study. With increasing $g_{\mathrm{Ca}, \mathrm{L}}$, the $\mathrm{Ca}^{2+}$ transient and $F_{\text {norm }}$ increase, but APD is not affected. Thus, the increase in APD observed in experiments cannot be reproduced by increasing $g_{\mathrm{Ca}, \mathrm{L}}$ alone. Since no changes in peak $I_{\mathrm{Ca}, \mathrm{L}}$ current size have been observed in experiments after ventricular pacing, ${ }^{7,27,49}$ also scaling $g_{\mathrm{Ca}, \mathrm{L}}$ is not considered further. 
TABLE 2. Effect of parameter $\rho$ on electrophysiology and contractile force.

\begin{tabular}{lccccccc}
\hline$\rho(-)$ & $V_{\text {rest }}(\mathrm{mV})$ & $\left(\mathrm{d} V_{\text {mem }} / \mathrm{d} t\right)_{\max }\left(\mathrm{V} \mathrm{s}^{-1}\right)$ & $\mathrm{APA}(\mathrm{mV})$ & $\mathrm{APD}_{90}(\mathrm{~ms})$ & $\mathrm{APD}_{50}(\mathrm{~ms})$ & {$\left[\mathrm{Ca}^{2+}\right]_{\mathrm{i}, \max }(\mu \mathrm{M})$} & $F_{\text {norm, max }}(-)$ \\
\hline-1.0 & -81.7 & 161 & 105.8 & 197 & 43 & 0.44 & 0.09 \\
-0.5 & -81.5 & 162 & 105.7 & 244 & 91 & 0.54 & 0.27 \\
0.0 & -80.9 & 163 & 105.2 & 311 & 190 & 1.11 & 0.79 \\
0.5 & -80.5 & 161 & 104.8 & 336 & 217 & 1.44 & 0.90 \\
1.0 & -80.0 & 156 & 104.4 & 393 & 264 & \\
\hline
\end{tabular}

$V_{\text {rest }}$, resting potential; $\left(\mathrm{d} V_{\text {mem }} / \mathrm{d} t\right)_{\max }$, maximum upstroke velocity; APA, action potential (AP) amplitude; $A P D_{90}$ and $A P D_{50}$, AP duration at $90 \%$ and $50 \%$ repolarization; $\left[\mathrm{Ca}^{2+}\right]_{\text {,max }}$, maximum intracellular $\mathrm{Ca}^{2+}$ concentration; $F_{\text {norm,max }}$, maximum normalized contractile force $\left(I_{\mathrm{CE}}=2.3 \mu \mathrm{m}\right)$.
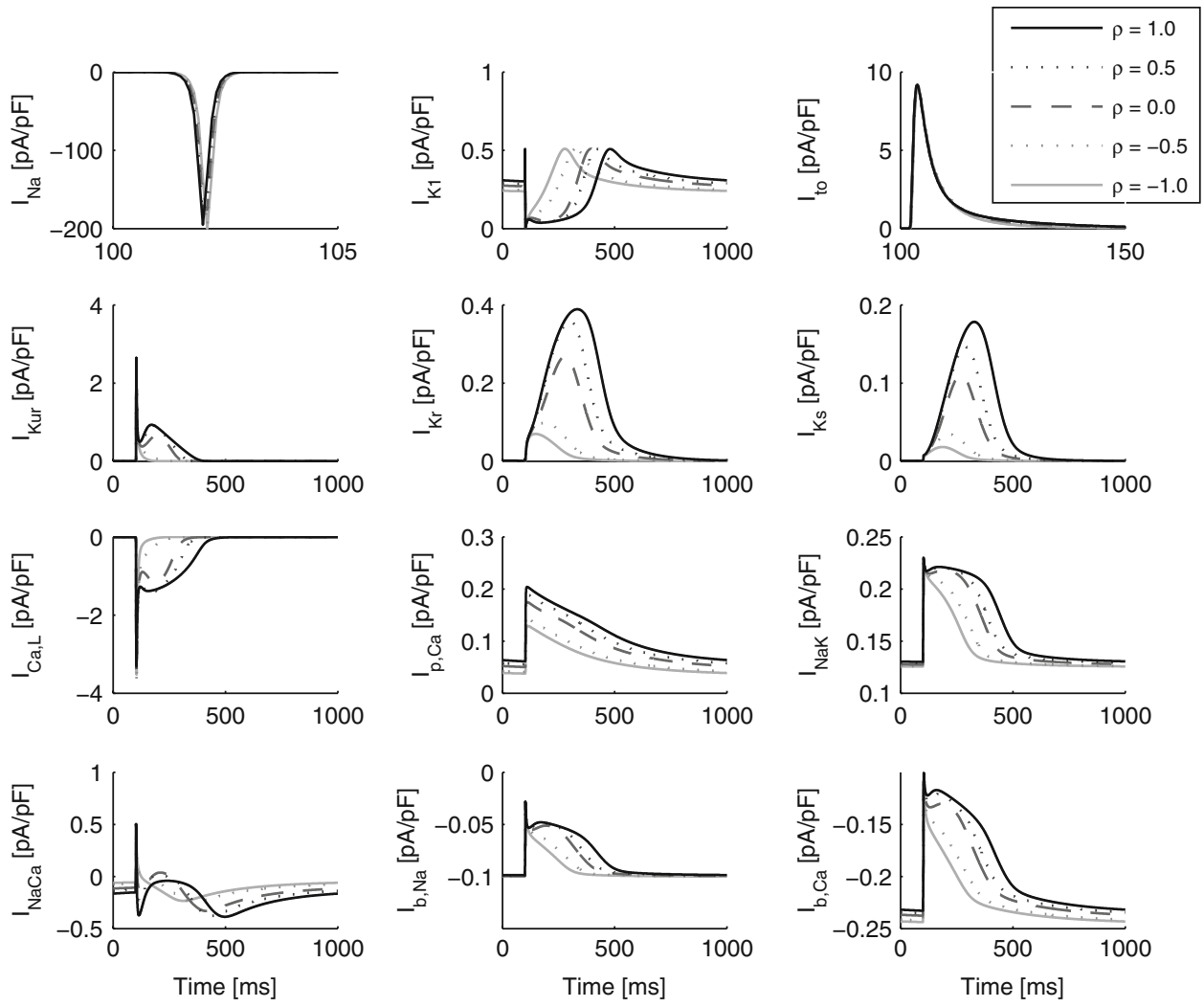

FIGURE 3. Effect of parameter $\rho$ on ionic membrane currents. Fast inward $\mathrm{Na}^{+}$current $\left(I_{\mathrm{Na}}\right)$, inward rectifier $\mathrm{K}^{+}$current $\left(I_{\mathrm{K} 1}\right)$, transient outward $\mathrm{K}^{+}$current $\left(I_{\mathrm{to}}\right)$, ultrarapid delayed rectifier $\mathrm{K}^{+}$current $\left(I_{\mathrm{Kur}}\right)$, rapid delayed rectifier $\mathrm{K}^{+}$current $\left(I_{\mathrm{Kr}}\right)$, slow delayed rectifier $\mathrm{K}^{+}$current $\left(I_{\mathrm{Ks}}\right)$, L-type $\mathrm{Ca}^{2+}$ current $\left(I_{\mathrm{Ca}, \mathrm{L}}\right), \mathrm{Ca}^{2+}$ pump current $\left(I_{\mathrm{p}, \mathrm{Ca}}\right), \mathrm{Na}^{+}-\mathrm{K}^{+}$pump current $\left(I_{\mathrm{NaK}}\right), \mathrm{Na}^{+} / \mathrm{Ca}^{2+}$ exchanger current $\left(I_{\mathrm{NaCa}}\right)$, background $\mathrm{Na}^{+}$current $\left(I_{\mathrm{b}, \mathrm{Na}}\right)$, and background $\mathrm{Ca}^{2+}$ current $\left(I_{\mathrm{b}, \mathrm{Ca}}\right)$ for $\rho=1.0,0.5,0.0,-0.5$, and -1.0 . A stimulus current was applied at $100 \mathrm{~ms}$. Corresponding APs are presented in the top-right panel of Fig. 2. Note the different time scales for $I_{\mathrm{Na}}$ and $I_{\mathrm{to}}$.

In Table 2, AP characteristics, peak $\left[\mathrm{Ca}^{2+}\right]_{\mathrm{i}}$, and peak $F_{\text {norm }}\left(l_{\mathrm{CE}}=2.3 \mu \mathrm{m}\right)$ are presented for various values of $\rho$. With increasing $\rho, \mathrm{APD}_{90}, \mathrm{APD}_{50}$, peak $\left[\mathrm{Ca}^{2+}\right]_{\mathrm{i}}$, and peak $F_{\text {norm }}$ all increase. Resting membrane potential $\left(V_{\text {rest }}\right)$, maximum upstroke velocity $\left(\left(\mathrm{d} V_{\operatorname{mem}} / \mathrm{d} t\right)_{\max }\right)$, and AP amplitude (APA) are not significantly different for different values of $\rho$.

In Fig. 3, the 12 ionic membrane currents of the Courtemanche-Ramirez-Nattel model are plotted for parameter $\rho=-1.0,0.5,0.0,0.5$, and 1.0. Except for $I_{\mathrm{Na}}$ and $I_{\mathrm{to}}$, all currents are changed in response to changes in parameter $\rho . I_{\mathrm{Na}}$ and $I_{\mathrm{to}}$ are affected little, because they mainly play a role during depolarization and early repolarization. All other currents contribute to the plateau and repolarization phases and are affected by changes in $I_{\mathrm{Ca}, \mathrm{L}}$ kinetics.

\section{Single Cell Cardiac Cycle Simulation}

In Fig. $4, F_{\text {norm }}, T_{\mathrm{CE}}, T_{\text {segment }}, l_{\mathrm{CE}}$, strain, and the stress-strain loop are shown for $\rho=0.0, \rho=0.5$, and $\rho=1.0\left(T_{\text {rest }}=0.5 \mathrm{kPa}, T_{\text {preload }}=1 \mathrm{kPa}\right.$, and 

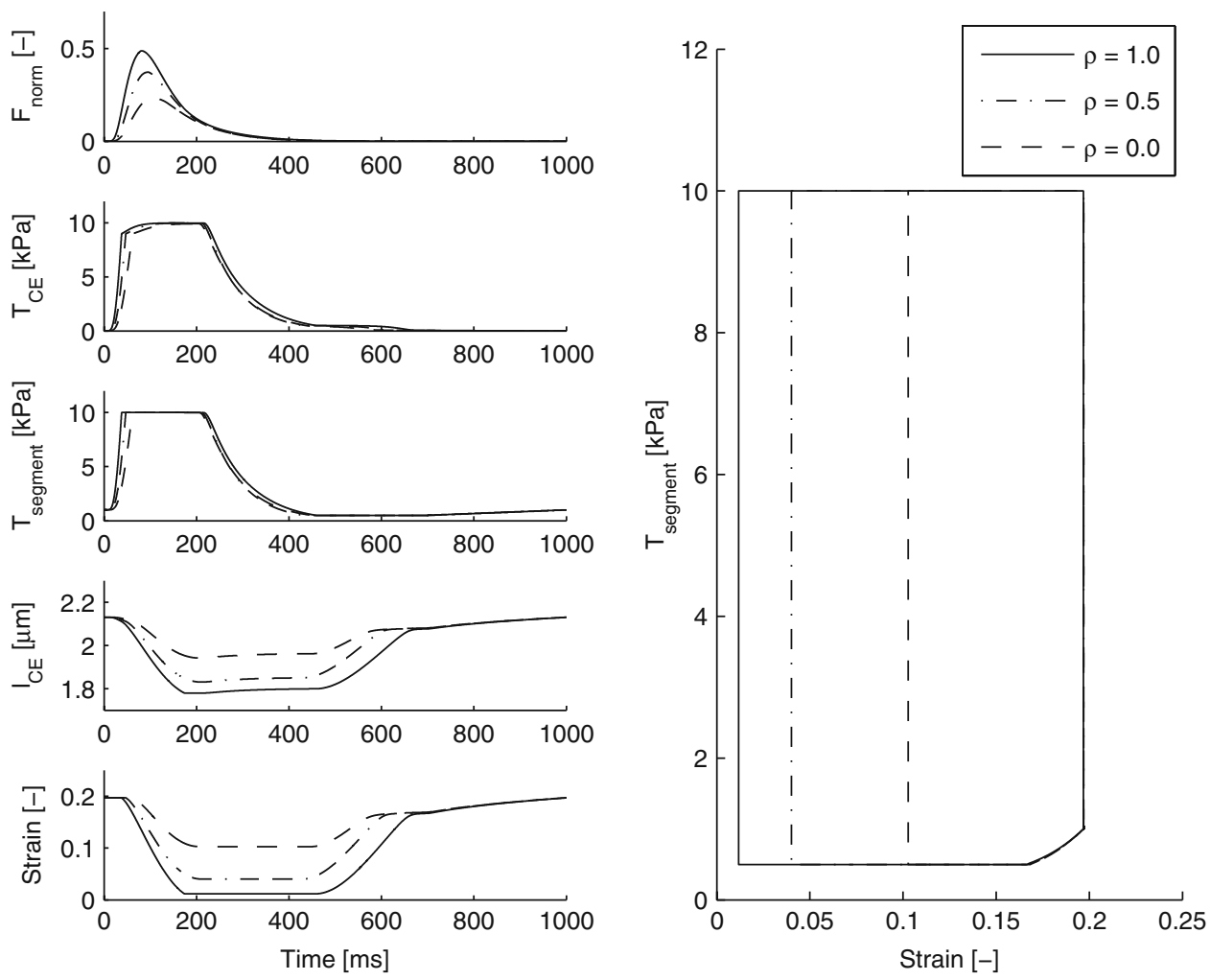

FIGURE 4. Effect of parameter $\rho$ on mechanical behavior during cardiac cycle (single segment). $T_{\text {rest }}=0.5 \mathrm{kPa}, T_{\text {preload }}=1 \mathrm{kPa}$, and $T_{\text {afterload }}=10 \mathrm{kPa} ; \rho=0.0,0.5$, and 1.0. Left: $F_{\text {norm, }}$, active tension $\left(T_{\mathrm{CE}}\right), T_{\text {segment }}, I_{\mathrm{CE}}$, and strain. Right: stress-strain loop. The cell was electrically stimulated at the beginning of isovolumic contraction at simulation time $t=0 \mathrm{~ms}$.

$\left.T_{\text {afterload }}=10 \mathrm{kPa}\right) . F_{\text {norm }}$ is larger for larger values of $\rho$, which results in an increased shortening during ejection and more stroke work. To investigate the effect of applied load on mechanical behavior, we performed a series of single cell simulations with var-

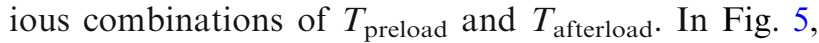
the effect of varying $T_{\text {preload }}$ and $T_{\text {afterload }}$ on the stressstrain loop is shown for $\rho=0.0, \rho=0.5$, and $\rho=1.0$. Shortening increases for larger values of $T_{\text {preload}}$, because the segment is more stretched prior to contraction (Frank-Starling mechanism). On the other hand, shortening decreases for increasing $T_{\text {afterload }}$, which is explained by the fact that the sarcomeres need to generate more force to be able to shorten. These results are in agreement with the work-loop style contractions in the experiments by Iribe et al. ${ }^{24}$

\section{Remodeling of $I_{C a, L}$ in a Cardiac Fiber}

To investigate the effect of remodeling of $I_{\mathrm{Ca}, \mathrm{L}}$ on electrical and mechanical behavior, we consider Fibers $\mathrm{A}, \mathrm{B}$, and $\mathrm{C}$ with $T_{\text {rest }}=0.5 \mathrm{kPa}, T_{\text {preload }}=1 \mathrm{kPa}$, and $T_{\text {afterload }}=10 \mathrm{kPa}$. In Fig. $6, W_{\text {ext }}, W_{\text {tot }}$, parameter $\rho$, action potential duration $\left(\mathrm{APD}_{-60} \mathrm{mV}\right)$, and time of repolarization $\left(t_{\text {repol }}\right)$ are shown for each location along the fibers without remodeling, with remodeling controlled by $W_{\text {ext }}$, and with remodeling controlled by $W_{\text {tot }}$. Without remodeling, $W_{\text {ext }}$ is small for early-activated segments in Fiber A and negative for early-activated segments in Fibers B and C. With remodeling, $W_{\text {ext }}$ and $W_{\text {tot }}$ are increased for earlyactivated segments and decreased for later-activated segments. Although $W_{\text {ext }}$ is positive for the earlyactivated segments in Fibers $\mathrm{B}$ and $\mathrm{C}$, the reference value ( $W_{\text {ext }}$ in the center) is not reached, since $\rho$ reaches its maximum value of 1.0. Electrical remodeling has no effect on the conduction velocity; the time of depolarization is the same with and without remodeling (not shown).

As expected, remodeling affects the APD. APD $-60 \mathrm{mV}$ increases for early-activated segments and decreases for later-activated segments. In Fiber $\mathrm{C}, \mathrm{APD}_{-60} \mathrm{mv}$ also increases for later-activated segments in case remodeling is controlled by $W_{\text {tot }}$. These changes in APD result in a decreased dispersion of repolarization in Fibers B and C. In Fig. 6 (bottom) it can be observed that without remodeling, the repolarization wave starts at the stimulation site and travels in the same direction as the depolarization wave to the other end. With remodeling in Fiber A, repolarization starts at the other end, and hence the repolarization wave travels in the opposite direction from the depolarization wave. 

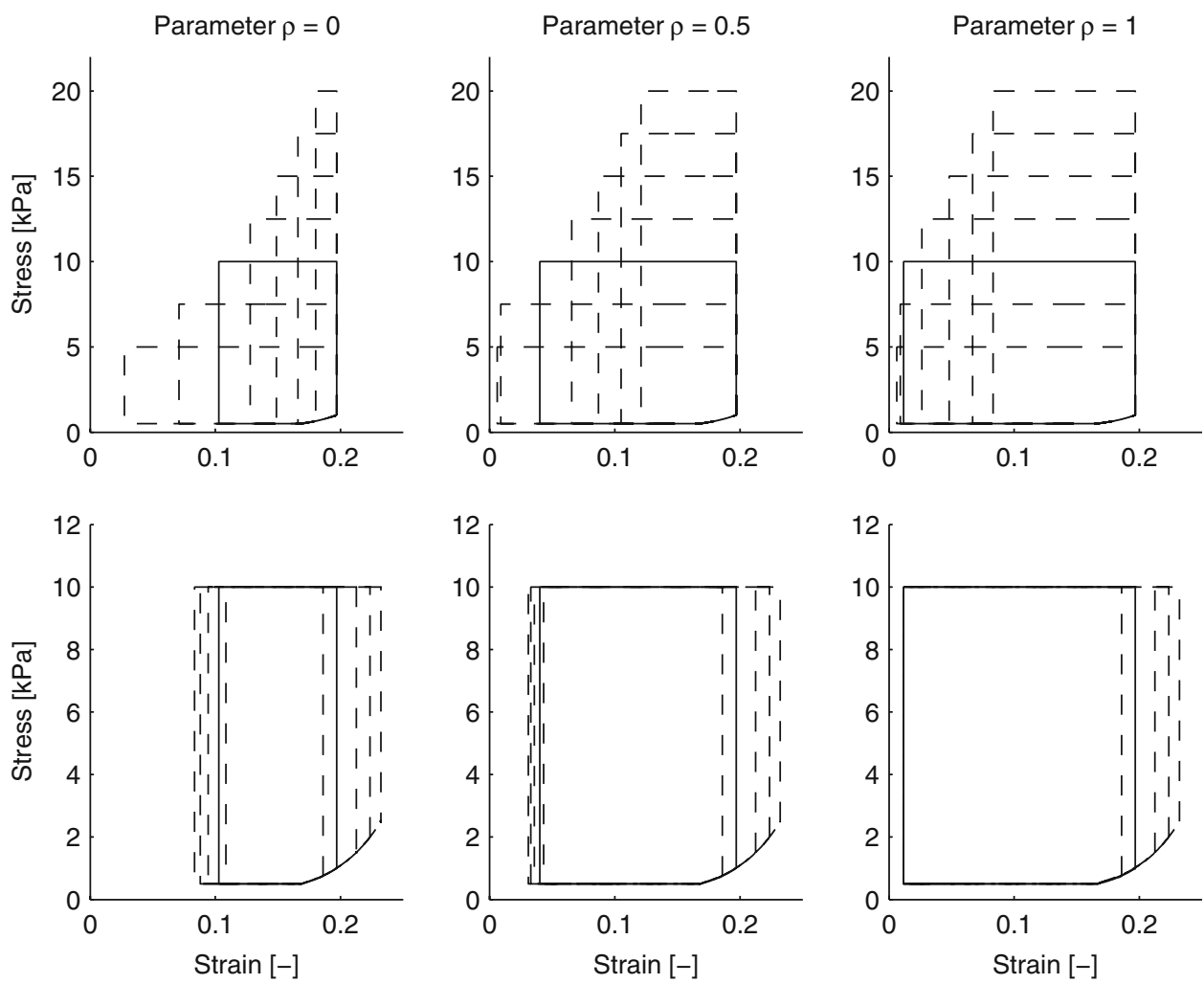

FIGURE 5. Effect of varying $T_{\text {preload }}$ and $T_{\text {afterload }}$ for $\rho=0, \rho=0.5$, and $\rho=1$. Top panels: $T_{\text {rest }}=0.5 \mathrm{kPa}, T_{\text {preload }}=1 \mathrm{kPa}$, and $T_{\text {afterload }}$ ranges between 5 and $20 \mathrm{kPa}$. Bottom panels: $T_{\text {rest }}=0.5 \mathrm{kPa}, T_{\text {afterload }}=10 \mathrm{kPa}$, and $T_{\text {preload }}$ ranges between 0.75 and $2.5 \mathrm{kPa}$. Solid lines indicate $T_{\text {preload }}=1 \mathrm{kPa}$ and $T_{\text {afterload }}=10 \mathrm{kPa}$.

With remodeling in the Fibers $\mathrm{B}$ and $\mathrm{C}$, the repolarization wave starts near the center and travels in both directions, partly in opposite direction from the depolarization wave.

Figure 7 illustrates the effect of $I_{\mathrm{Ca}, \mathrm{L}}$ remodeling on $V_{\text {mem }},\left[\mathrm{Ca}^{2+}\right]_{\mathrm{i}}, F_{\text {norm }}, T_{\mathrm{CE}}, T_{\mathrm{PE}}$, and strain for three segments of Fiber A. Without remodeling, the APs of the three segments have similar morphology and duration. However, with remodeling the AP of the segment at $0.5 \mathrm{~cm}$ envelops the APs of the other two segments. This is also the case for the $\mathrm{Ca}^{2+}$ transient. With remodeling, $F_{\text {norm }}$ is increased for early-activated segments such that these segments are able to shorten more during ejection. On the other hand, $F_{\text {norm }}$ is decreased for later-activated segments, which results in a decreased $T_{\mathrm{CE}}$. During ejection, $T_{\mathrm{PE}}$ is larger to compensate for the decrease in $T_{\mathrm{CE}}$, and thus the strain is increased for these segments. The overall result is that later-activated segments exhibit less shortening, while early-activated segments shorten more. To quantify shortening during ejection, we compare the stretch at end of ejection $\left(\lambda_{\text {ee }}\right)$ to the stretch at begin of ejection $\left(\lambda_{\text {be }}\right)$ for each segment. Without remodeling $\lambda_{\text {ee }} / \lambda_{\text {be }}=0.97,0.92$, and 0.87 for the segments located at $0.5,1.5$, and $2.5 \mathrm{~cm}$, respectively, while with remodeling $\lambda_{\mathrm{ee}} / \lambda_{\text {be }}$ is between 0.88 and 0.92 for all segments. Thus, a more homogeneous shortening of Fiber A is obtained with remodeling.

In Figs. 8 and $9, V_{\text {mem }},\left[\mathrm{Ca}^{2+}\right]_{i}, F_{\text {norm }}, T_{\mathrm{CE}}, T_{\mathrm{PE}}$, and strain for three segments of the Fibers $\mathrm{B}$ and $\mathrm{C}$ are presented. Without remodeling, the early-activated segments stretch the later-activated segments, which leads to an inhomogeneous contraction. With remodeling of Fiber $\mathrm{B}$, the $\mathrm{AP}$ and $\mathrm{Ca}^{2+}$ transient of the early-activated segments envelops the AP and $\mathrm{Ca}^{2+}$ transient of the later-activated segments and a more homogeneous shortening is obtained during ejection. In the case of Fiber $\mathrm{C}$, depolarization of the lateractivated segments is delayed so that part of the shortening occurs after ejection and does not contribute to the shortening of the fiber. In case electrical remodeling is controlled by $W_{\text {tot }}$, the $\rho_{n}$ are increased for the later-activated segments, which results in more shortening during ejection. The large differences in strain during ejection between early and later-activated segments are in agreement with the large differences in peak systolic strains measured by Jeyaraj et al. ${ }^{26}$ after 4 weeks of ventricular pacing. Prolongation of the APD occurs for both early and later-activated segments, but not for intermediate segments (Fig. 6), which is also in agreement with the experimental observations by Jeyaraj et $a l^{26}$ 

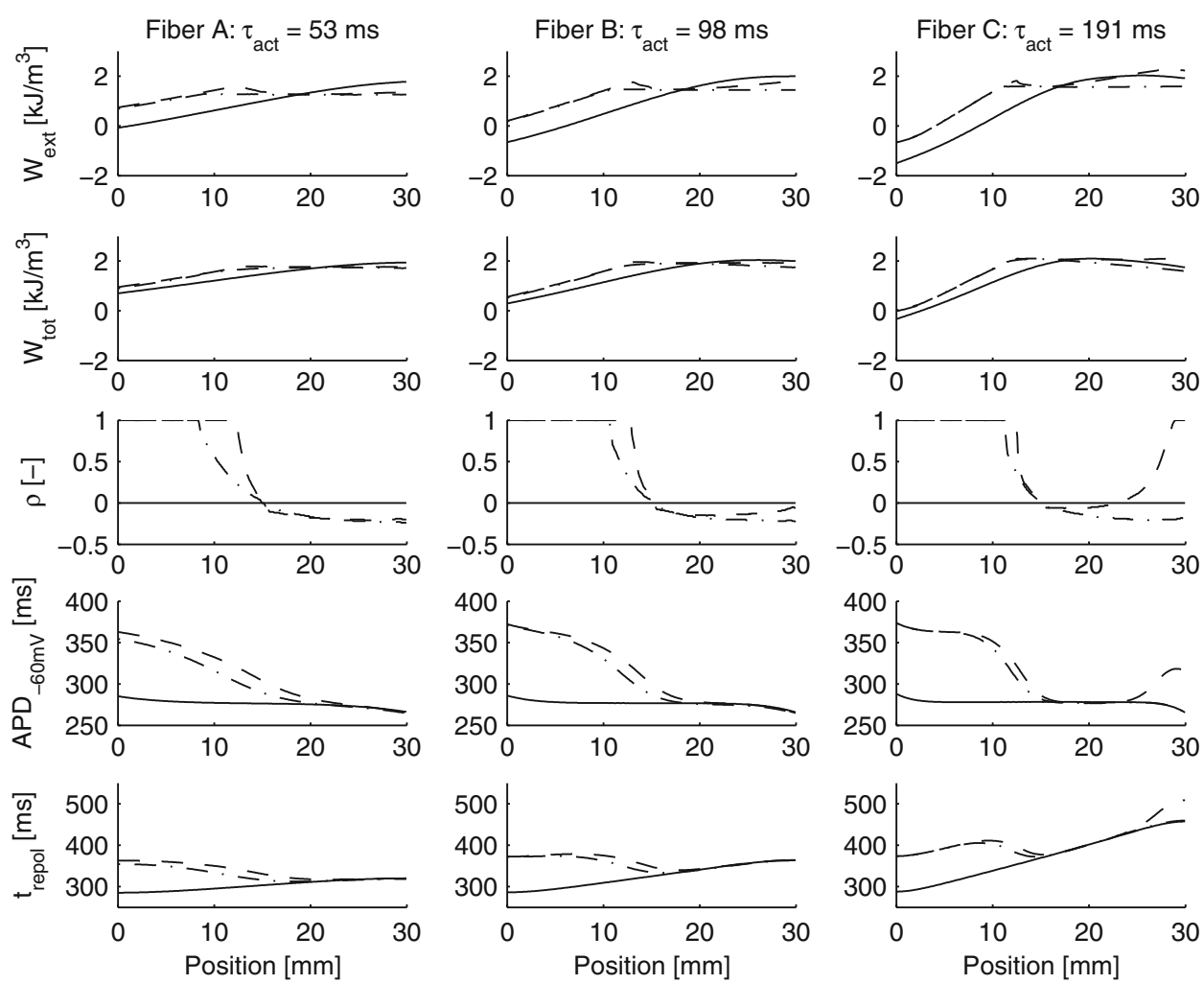

FIGURE 6. Effect of electrical remodeling of $I_{\mathrm{Ca}, \mathrm{L}}$ for Fibers $\mathrm{A}, \mathrm{B}$, and $\mathrm{C}\left(T_{\text {rest }}=0.5 \mathrm{kPa}, T_{\text {preload }}=1 \mathrm{kPa}, T_{\text {afterload }}=10 \mathrm{kPa}\right)$. From top to bottom: external stroke work density $\left(W_{\text {ext }}\right)$, total stroke work density $\left(W_{\text {tot }}\right)$, parameter $\rho$, action potential duration $\left(A P D_{-60} \mathrm{mv}\right)$, and repolarization time $\left(t_{\text {repol }}\right)$. APD $-60 \mathrm{mv}$ is defined as the time during which $V_{\text {mem }}$ is larger than $-60 \mathrm{mV}$ and $t_{\text {repol }}$ is the time at which $V_{\text {mem }}$ becomes lower than $-60 \mathrm{mV}$. Data are plotted without remodeling (solid line), after remodeling controlled by $W_{\text {ext }}$ (dash-dotted line), and after remodeling controlled by $W_{\text {tot }}$ (dashed line). A stimulus current was applied to the segment at $0 \mathrm{~mm}$ at $0 \mathrm{~ms} . \tau_{\text {act }}$ indicates time of complete activation of the fiber.

In Fig. 10, the stress-strain loops with and without remodeling are presented for the same segments of the three fibers. Without remodeling, $W_{\text {ext }}$, which is by definition the area enclosed by the stress-strain loop, is small or negative for the early-activated segments. However, with remodeling the area enclosed by the stress-strain loop is enlarged, indicating that these segments shorten more during ejection. On the other hand, the shortening of the later-activated segments is decreased with remodeling. An exception is the lateractivated segment of Fiber $\mathrm{C}$, which shortens more during ejection when remodeling is controlled by $W_{\text {tot }}$.

Finally, in Fig. 11, stress, strain, and the stressstrain loop for the entire fiber are presented without and with remodeling. Relative to the fiber length at begin of ejection, fiber shortening increases from 7-8\% without remodeling to $10-11 \%$ with remodeling.

\section{DISCUSSION}

\section{What Triggers Electrical Remodeling?}

Libbus and Rosenbaum ${ }^{41}$ showed that electrical remodeling can be triggered by changing the stimulation rate as well as by changing the activation sequence. The observed changes in APD and AP morphology are, however, different. Increasing the stimulation rate leads to a shortening of the APD, while changing the activation sequence leads to prolongation of the APD. In both cases, the notch of the AP is reduced, indicating a reduction in $I_{\mathrm{to}}{ }^{41}$ Libbus et al. ${ }^{42}$ suggest that remodeling of $I_{\text {to }}$ may be explained by changes in electrotonic load. Jeyaraj et al. ${ }^{26}$ recently proposed mechanoelectric feedback as a mechanism for electrical remodeling. Based on their observation that APD is prolonged near the site of stimulation and also in remote regions, it is unlikely that electrical remodeling is explained by electrotonic interactions. ${ }^{26}$ Based on their measurements of circumferential strain, Jeyaraj et $a l .{ }^{26}$ propose that electrical remodeling is related to the distribution of strain. Sosunov et al. ${ }^{62}$ found that electrical remodeling can be inhibited either by reducing mechanical load or by reducing contractility, indicating that changes in mechanical load are involved. Patberg et al. ${ }^{48}$ suggest that angiotensin II is a likely candidate to trigger $I_{\mathrm{Ca}, \mathrm{L}}$ remodeling, since its release is altered by changes in stretch and it affects $I_{\mathrm{Ca}, \mathrm{L}}$. Local changes in the stress-strain loop may lead 

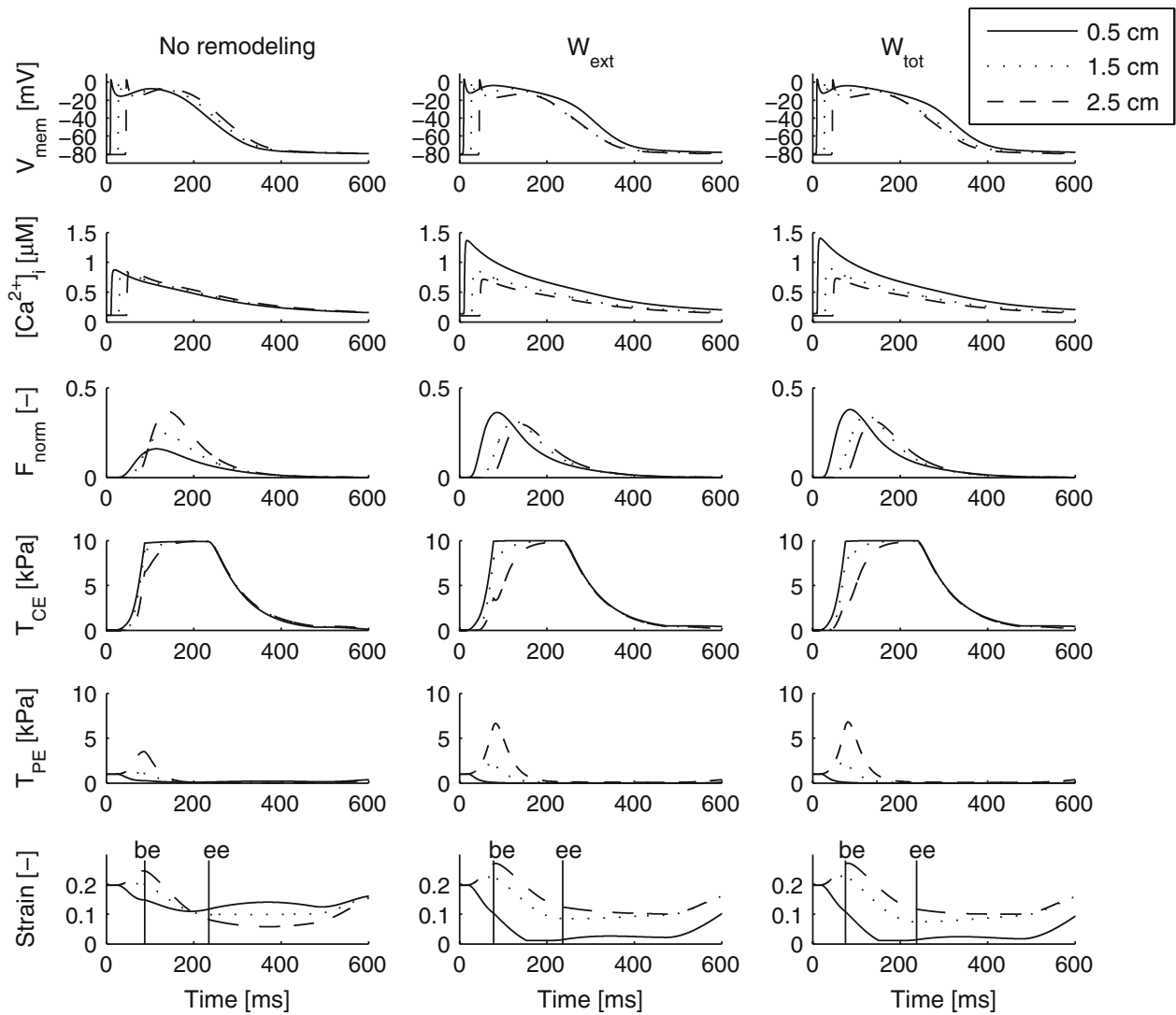

FIGURE 7. Fiber A: effect of electrical remodeling of $I_{\mathrm{Ca}, \mathrm{L}}$ controlled by $W_{\text {ext }}$ and by $W_{\text {tot }}$ on individual segments $\left(T_{\text {rest }}=0.5 \mathrm{kPa}\right.$, $T_{\text {preload }}=1 \mathrm{kPa}$, and $\left.T_{\text {afterload }}=10 \mathrm{kPa}\right) . V_{\text {mem, }},\left[\mathrm{Ca}^{2+}\right]_{\mathrm{i}}, F_{\text {norm }}, T_{\mathrm{CE}}, T_{\mathrm{PE}}$, and strain are plotted for segments located at 0.5 , 1.5 , and $2.5 \mathrm{~cm}$. Left: without remodeling. Center: remodeling controlled by $W_{\text {ext }}$. Right: remodeling controlled by $W_{\text {tot. }}$ The vertical lines in the lower panels indicate begin of ejection (be) and end of ejection (ee). A stimulus current was applied to the segment at $0.0 \mathrm{~cm}$ at 0 ms.

to changes in angiotensin II release and eventually affect $I_{\mathrm{Ca}, \mathrm{L}}$ and calcium homeostasis., ${ }^{7,48,58}$

In our model, reduction of $g_{\text {to }}$ leads to disappearance of the notch in the action potential as well as a reduced APD (Fig. 2). After changing the activation sequence for 20 days, Yu et al. $^{72}$ observed disappearance of the notch and APD prolongation. Jeyaraj et ll $^{26}$ observed APD prolongation without disappearance of the notch, indicating that $I_{\text {to }}$ may not be the only ionic current that changes when the activation sequence is changed. Kääb et al. ${ }^{27}$ found a reduced notch and prolonged APD after 3-4 weeks of ventricular pacing. They also found a reduction in $I_{\mathrm{to}}$, but did not find any differences in $I_{\mathrm{Ca}, \mathrm{L}}$. Kääb et $a l^{27}$ hypothesized that downregulation of $I_{\text {to }}$ is at least partially responsible for the prolongation of the APD. Shvilkin et al. ${ }^{60}$ observed APD prolongation in both epicardium (which has large $I_{\mathrm{to}}$ ) and endocardium (which has small $I_{\mathrm{to}}$ ), and no change in APD in midmyocardium (which has prominent $I_{\mathrm{to}}$ ). These results suggest that other ionic currents play an important role in electrical remodeling. ${ }^{60}$
Rubart et al. ${ }^{56}$ reported a prolonged APD and a reduced notch after one hour of ventricular pacing in dogs. They found a reduction in $I_{\text {to }}$ as well as an increase in peak $I_{\mathrm{Ca}, \mathrm{L}}{ }^{56}$ After 21 days of ventricular pacing, Plotnikov et al. ${ }^{49}$ observed a more positive $I_{\mathrm{Ca}, \mathrm{L}}$ activation threshold and slower inactivation in epicardial myocytes, but $I_{\mathrm{Ca}, \mathrm{L}}$ current size was not changed. Based on these observations, we hypothesized that $I_{\mathrm{to}}$ conductance $\left(g_{\mathrm{to}}\right)$ and $I_{\mathrm{Ca}, \mathrm{L}}$ kinetics, but not $I_{\mathrm{Ca}, \mathrm{L}}$ conductance $\left(g_{\mathrm{Ca}, \mathrm{L}}\right)$, are affected after changing the activation sequence. Although $I_{\text {to }}$ remodeling is probably related to changes in $I_{\mathrm{Ca}, \mathrm{L}}$, the relation between $I_{\mathrm{to}}$ and $I_{\mathrm{Ca}, \mathrm{L}}$ during electrical remodeling is not clear. Since reducing $g_{\text {to }}$ has little effect on the calcium transient in our model, we decided to adapt $I_{\mathrm{Ca}, \mathrm{L}}$ kinetics, but not $I_{\mathrm{to}}$ conductance, when simulating electrical remodeling.

Effect of Electrical Remodeling on $\mathrm{Ca}^{2+}$ and Mechanics

In our model, a larger $I_{\mathrm{Ca}, \mathrm{L}}$ current and slower decrease of $I_{\mathrm{Ca}, \mathrm{L}}$ during the plateau phase corresponds 

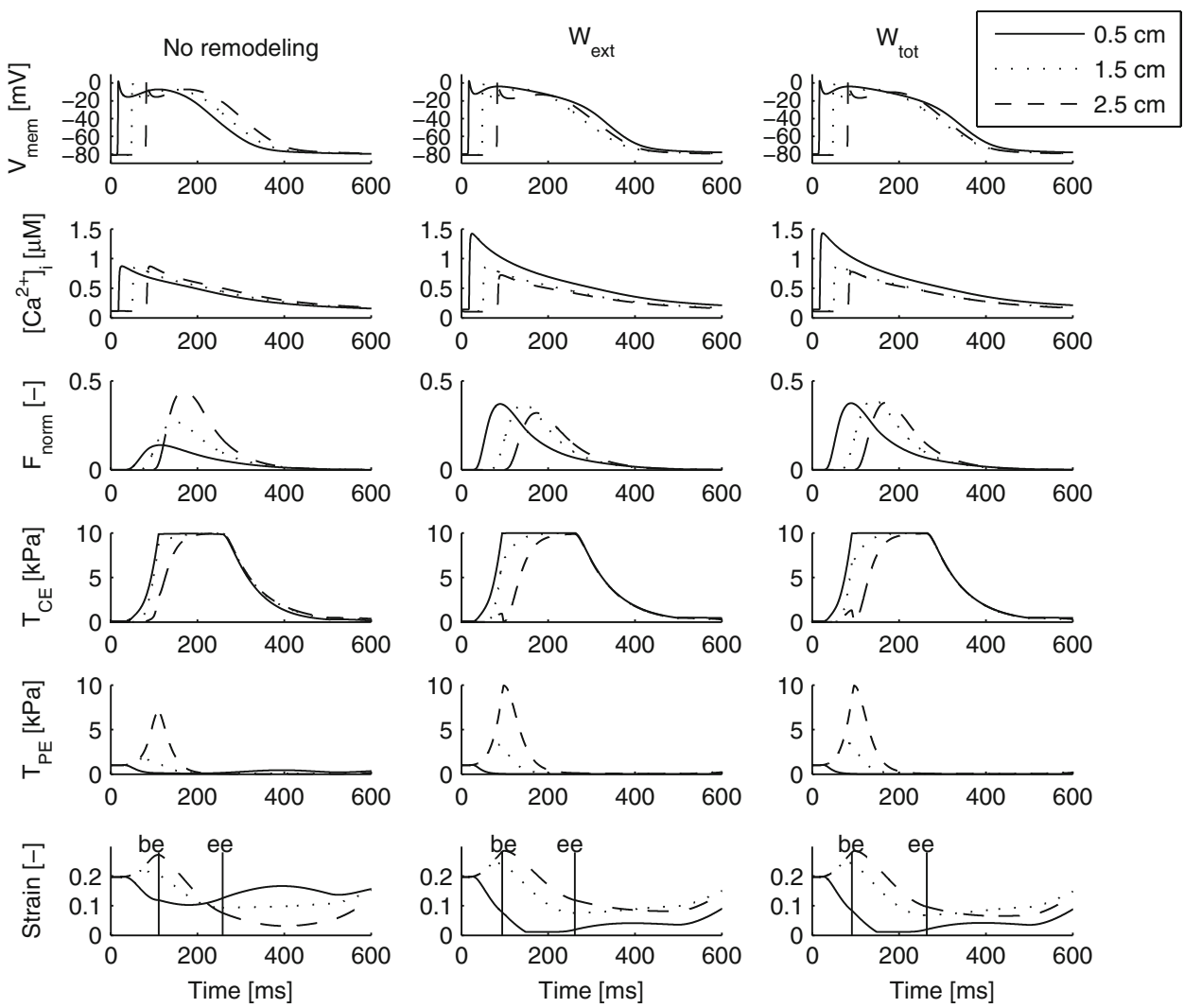

FIGURE 8. Fiber B: effect of electrical remodeling of $I_{\mathrm{Ca}, \mathrm{L}}$ controlled by $W_{\text {ext }}$ and by $W_{\text {tot }}$ on individual segments $\left(T_{\text {rest }}=0.5 \mathrm{kPa}\right.$, $T_{\text {preload }}=1 \mathrm{kPa}$, and $\left.T_{\text {afterload }}=10 \mathrm{kPa}\right) . V_{\text {mem }},\left[\mathrm{Ca}^{2+}\right]_{\mathrm{i}}, F_{\text {norm }}, T_{\mathrm{CE}}, T_{\mathrm{PE}}$, and strain are plotted for segments located at $0.5,1.5$, and $2.5 \mathrm{~cm}$. Left: without remodeling. Center: remodeling controlled by $W_{\text {ext. }}$ Right: remodeling controlled by $W_{\text {tot. }}$ The vertical lines in the lower panels indicate begin of ejection (be) and end of ejection (ee). A stimulus current was applied to the segment at $0.0 \mathrm{~cm}$ at 0 ms.

with a positive value of remodeling parameter $\rho$ and leads to an increased intracellular $\mathrm{Ca}^{2+}$ concentration and APD prolongation (Fig. 2). Plotnikov et al. ${ }^{49}$ observed a shift of $10 \mathrm{mV}$ in $I_{\mathrm{Ca}, \mathrm{L}}$ activation and an increase in $\mathrm{APD}_{90}$ of $65 \mathrm{~ms}$. In our model, a shift of $10 \mathrm{mV}$ in $I_{\mathrm{Ca}, \mathrm{L}}$ activation corresponds with an increase of $82 \mathrm{~ms}$ in $\mathrm{APD}_{90}$ (Table 2). Changing $I_{\mathrm{Ca}, \mathrm{L}}$ kinetics in our model affects the calcium transient and thus the amount of stroke work. The increase in $I_{\mathrm{Ca}, \mathrm{L}}$ results in an increased $\left[\mathrm{Ca}^{2+}\right]_{\mathrm{i}}$ during the AP and in an increased steady-state concentration of $\mathrm{Ca}^{2+}$ in the SR uptake compartment, which leads to an increased $\mathrm{Ca}^{2+}$ release and explains the increased $\mathrm{Ca}^{2+}$ transient.

The effect of electrical remodeling on the Fibers A and $\mathrm{B}$ can be characterized as follows. Early-activated segments are less stretched than later-activated segments before they start to contract. According to the Frank-Starling law, the tension generated by the earlyactivated segments is small. With remodeling, the early-activated segments generate more active tension and are able to shorten. On the other hand, the lateractivated segments generate less active tension (Figs. 7 and 8 ). The overall effect is that an increased and more homogeneous shortening of the fiber is obtained with electrical remodeling. Furthermore, the APD is increased in early-activated areas and decreased in lateractivated areas, which results in an inverse relationship between APD and activation time, and is in agreement with the results of Costard-Jäckle et al. ${ }^{11}$

Jeyaraj et $a l .{ }^{26}$ observed an increase in APD in areas close to the pacing site as well as in remote areas, while the APD was either normal or decreased in intermediate areas. We observed a similar distribution of the APD in Fiber $\mathrm{C}$ when remodeling was controlled by $W_{\text {tot }}$, but not when remodeling was controlled by $W_{\text {ext }}$. This difference in behavior is explained by the fact that $W_{\text {ext }}$ in the later-activated areas is larger than in the center of the fiber, whereas $W_{\text {tot }}$ is smaller than in the center. In both cases, the segments in the lateractivated areas exhibit the same amount of shortening. However, only in case remodeling is controlled by $W_{\text {tot }}$, most of the shortening occurs during ejection. We conclude that electrical remodeling of Fiber $\mathrm{C}$ controlled by $W_{\text {tot }}$ is in agreement with experimentally observed distributions of APD and may lead to homogeneous shortening during ejection. 

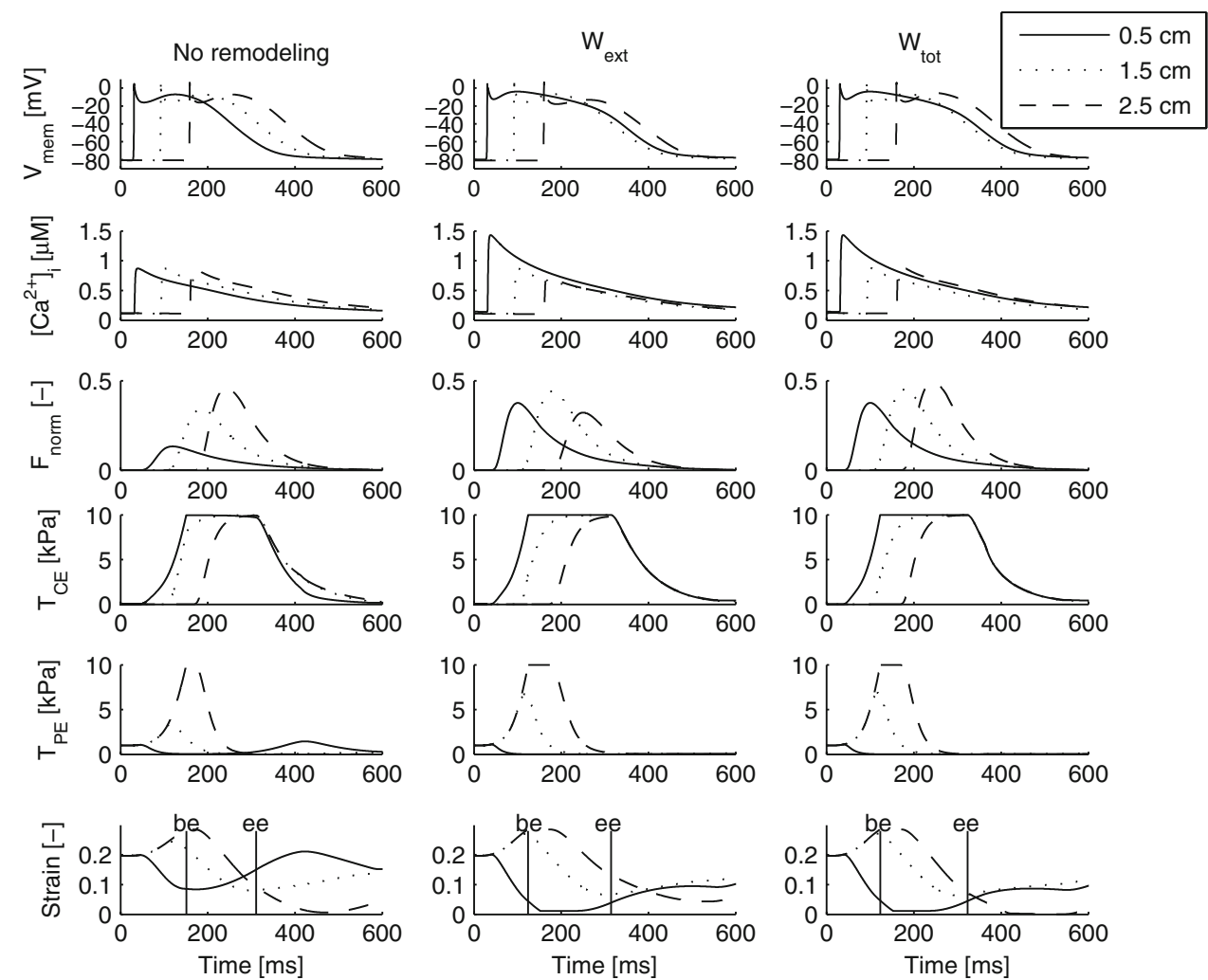

FIGURE 9. Fiber $\mathrm{C}$ : effect of electrical remodeling of $I_{\mathrm{Ca}, \mathrm{L}}$ controlled by $W_{\text {ext }}$ and by $W_{\text {tot }}$ on individual segments $\left(T_{\text {rest }}=0.5 \mathrm{kPa}\right.$, $T_{\text {preload }}=1 \mathrm{kPa}$, and $\left.T_{\text {afterload }}=10 \mathrm{kPa}\right) . V_{\text {mem, }},\left[\mathrm{Ca}^{2+}\right]_{\mathrm{i}}, F_{\text {norm }}, T_{\mathrm{CE}}, T_{\mathrm{PE}}$, and strain are plotted for segments located at $0.5,1.5$, and $2.5 \mathrm{~cm}$. Left: without remodeling. Center: remodeling controlled by $W_{\text {ext }}$ Right: remodeling controlled by $W_{\text {tot. }}$ The vertical lines in the lower panels indicate begin of ejection (be) and end of ejection (ee). A stimulus current was applied to the segment at $0.0 \mathrm{~cm}$ at $0 \mathrm{~ms}$.

\section{Transmural Heterogeneity in Excitation-Contraction Coupling}

Wang and Cohen $^{70}$ investigated transmural heterogeneity in the L-type $\mathrm{Ca}^{2+}$ channel in the canine left ventricle. Although the kinetic properties of the L-type $\mathrm{Ca}^{2+}$ current in epicardial and endocardial myocytes were not significantly different, they found a larger $I_{\mathrm{Ca}, \mathrm{L}}$ current in endocardial than in epicardial myocytes. ${ }^{70}$ Laurita et al. ${ }^{39}$ observed a longer duration of the $\mathrm{Ca}^{2+}$ transient in endocardial compared with epicardial myocytes from the canine left ventricle. Normal activation during sinus rhythm is represented by Fiber A. In this fiber, early-activated segments correspond with endocardial myocytes and later-activated segments with epicardial myocytes. With remodeling, a larger $I_{\mathrm{Ca}, \mathrm{L}}$ current and slower inactivation during the plateau phase is obtained for early-activated segments, which is in agreement with the experimental observations. However, to date, no experimental evidence exists for a transmural gradient in L-type $\mathrm{Ca}^{2+}$ kinetics in the normal heart.

Cordeiro et al. ${ }^{10}$ examined unloaded cell shortening of endocardial, midwall, and epicardial cells that were isolated from the canine left ventricle. Time to peak and latency to onset of contraction were shortest in epicardial and longest in endocardial cells, while an intermediate time to peak was observed in midwall cells. ${ }^{10}$ These differences in excitation-contraction coupling (ECC) are related to differences in time to peak and decay of the $\mathrm{Ca}^{2+}$ transient. ${ }^{10}$ In our model, time to peak of the $\mathrm{Ca}^{2+}$ transient is not significantly different when $I_{\mathrm{Ca}, \mathrm{L}}$ kinetics is changed (Fig. 2), which explains why the heterogeneity in ECC observed by Cordeiro et al. ${ }^{10}$ is not reproduced by our model.

\section{T Wave Concordance and Cardiac Memory}

Remodeling of $I_{\mathrm{Ca}, \mathrm{L}}$ kinetics in our model leads to significant changes in repolarization. In Fiber A, the repolarization wave travels in the opposite direction from the depolarization wave. In Fibers B and C, the repolarization wave starts near the center and travels in both directions along the fiber, partly in opposite direction from the depolarization wave. The changes in repolarization are explained by changes in APD and are in agreement with experimental observations. ${ }^{11,26}$ In the ventricles, the repolarization path is different from the depolarization path, which explains $\mathrm{T}$ wave 

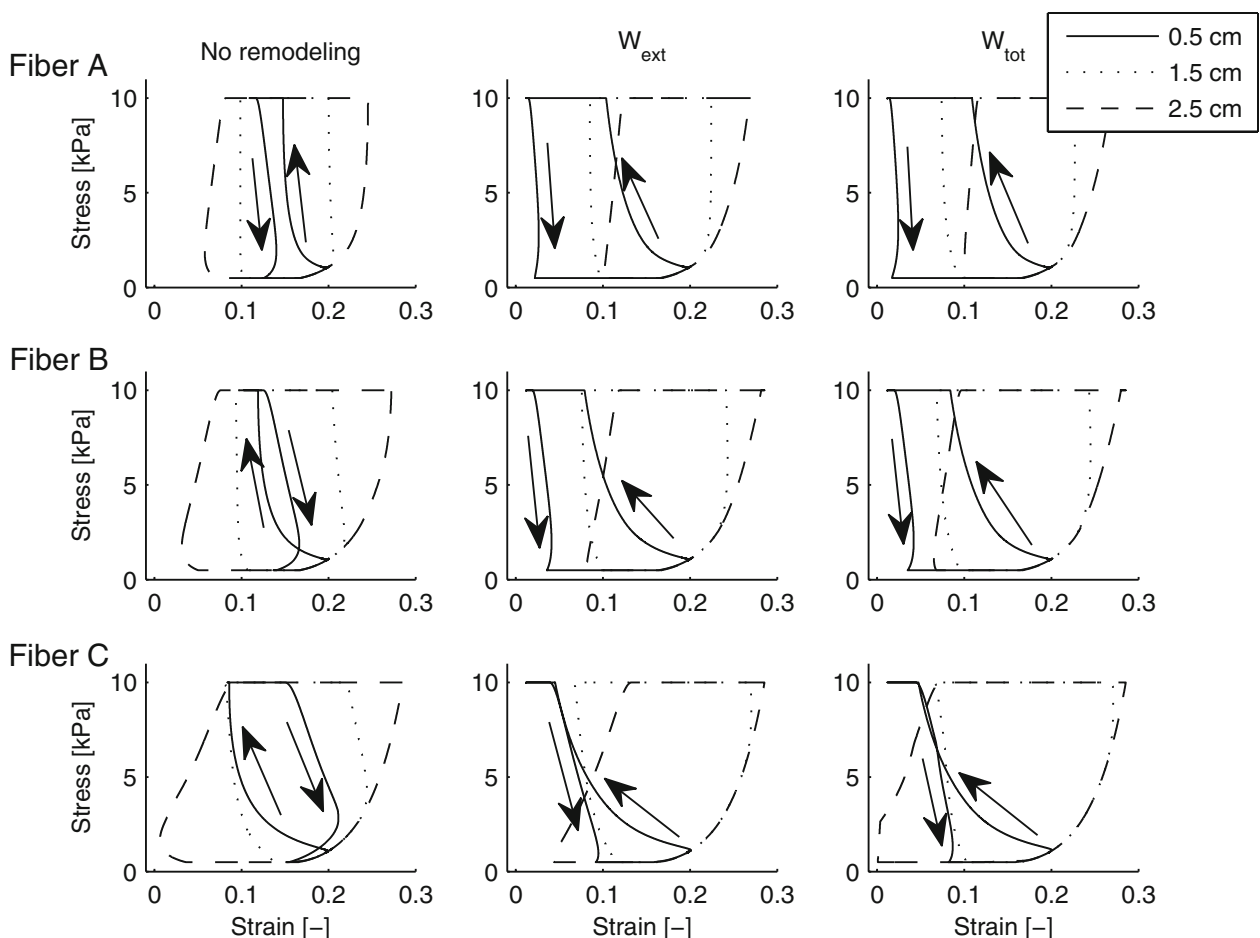

FIGURE 10. Effect of electrical remodeling of $I_{\mathrm{Ca}, \mathrm{L}}$ controlled by $W_{\text {ext }}$ and by $W_{\text {tot }}$ on the stress-strain loop for individual segments in Fibers A, B, and C ( $T_{\text {rest }}=0.5 \mathrm{kPa}, T_{\text {preload }}=1 \mathrm{kPa}$, and $\left.T_{\text {afterload }}=10 \mathrm{kPa}\right)$. Stress-strain loops are plotted for segments located at $0.5 \mathrm{~cm}$ (solid lines), at $1.5 \mathrm{~cm}$ (dotted lines), and at $2.5 \mathrm{~cm}$ (dashed lines). Left: without remodeling. Center: remodeling controlled by $W_{\text {ext }}$ Right: remodeling controlled by $W_{\text {tot. }}$ A stimulus current was applied to the segment at $0.0 \mathrm{~cm}$. The arrows indicate the direction of time for the segments located at $0.5 \mathrm{~cm}$ (solid lines).

concordance in the normal electrocardiogram (ECG). ${ }^{17}$ During ventricular pacing, the $\mathrm{T}$ wave changes, but $\mathrm{T}$ wave concordance reappears after several days when normal activation is restored ("cardiac memory"). ${ }^{55}$ Our model provides a possible explanation for this phenomenon by assuming that electrical remodeling of cardiomyocytes is triggered by changes in mechanical work.

\section{Ventricular Electromechanics}

Our simulation results show large differences in shortening of individual segments with and without remodeling. Without remodeling, early-activated segments shorten, then stretch and finally shorten again. Later-activated segments are first stretched, followed by a pronounced shortening (Figs. 7-9, left). With remodeling, a more homogeneous shortening of the segments is obtained (Figs. 7-9, center and right). Similar results were obtained by Nickerson et al. ${ }^{46}$ when they compared simulation results of ventricular electromechanics in the case that electrophysiology was modeled differently for endocardial, midwall, and epicardial myocytes to simulation results in the case that electrophysiology was modeled homogeneously. When electrophysiology was modeled homogeneously, a significant heterogeneity in strain was observed at the end of isovolumic contraction. However, when electrophysiology was modeled inhomogeneously, a reduction in transmural sarcomere length variation was observed during repolarization.

Prinzen et al. ${ }^{51}$ measured systolic fiber strain and external work at different locations in the left ventricle during right atrial pacing (RA pacing) and during left ventricular pacing (LV pacing). Compared with the normal values (RA pacing), strain and external work during LV pacing were approximately zero in regions near the pacing site, and gradually increased to more than twice the normal value in remote regions. ${ }^{51}$ These results are similar to our results for Fiber B without remodeling. With remodeling, we found a more homogeneous distribution of shortening and external work for Fibers A and B. In Fiber A, external work was almost homogeneous with remodeling (Fig. 6), which is in agreement with the measurements during RA pacing (normal stimulation) of Prinzen et al..$^{51}$

Ashikaga et al. ${ }^{4}$ investigated transmural dispersion of mechanics in vivo. They found that the onset of myofiber shortening was earliest in the endocardial layers, while the onset of myofiber relaxation was latest in the endocardial layers. In our model, the onset of relaxation in early-activated segments was delayed 

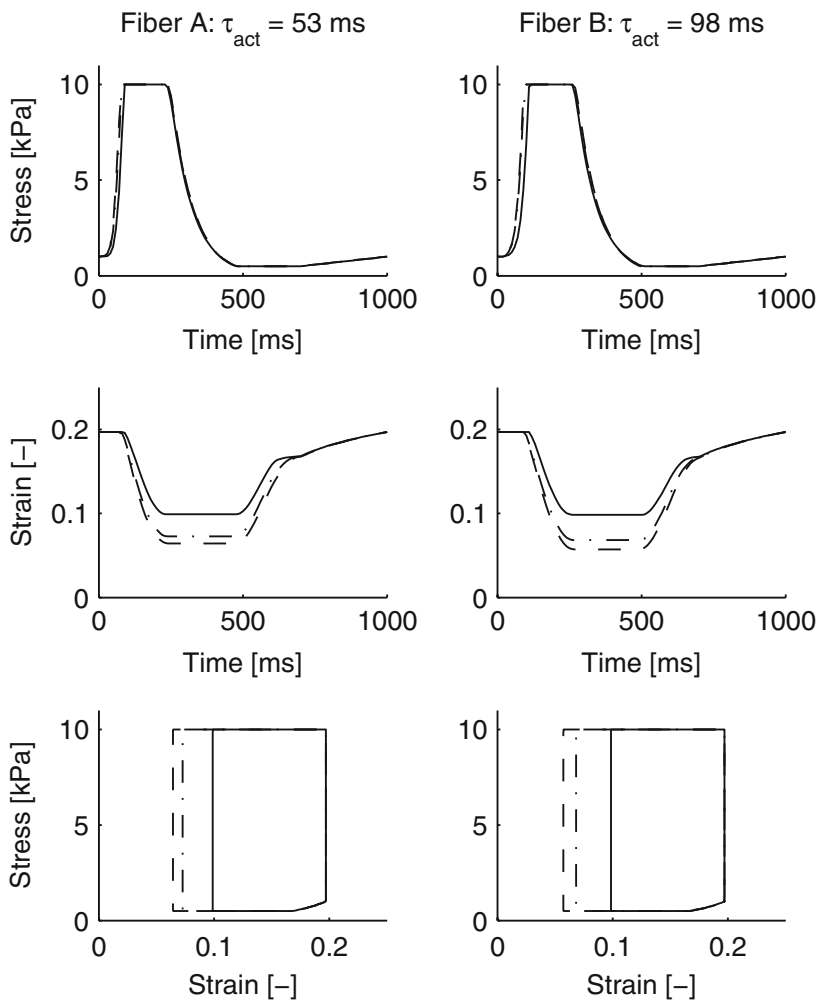

Fiber B: $\tau_{\text {act }}=98 \mathrm{~ms}$
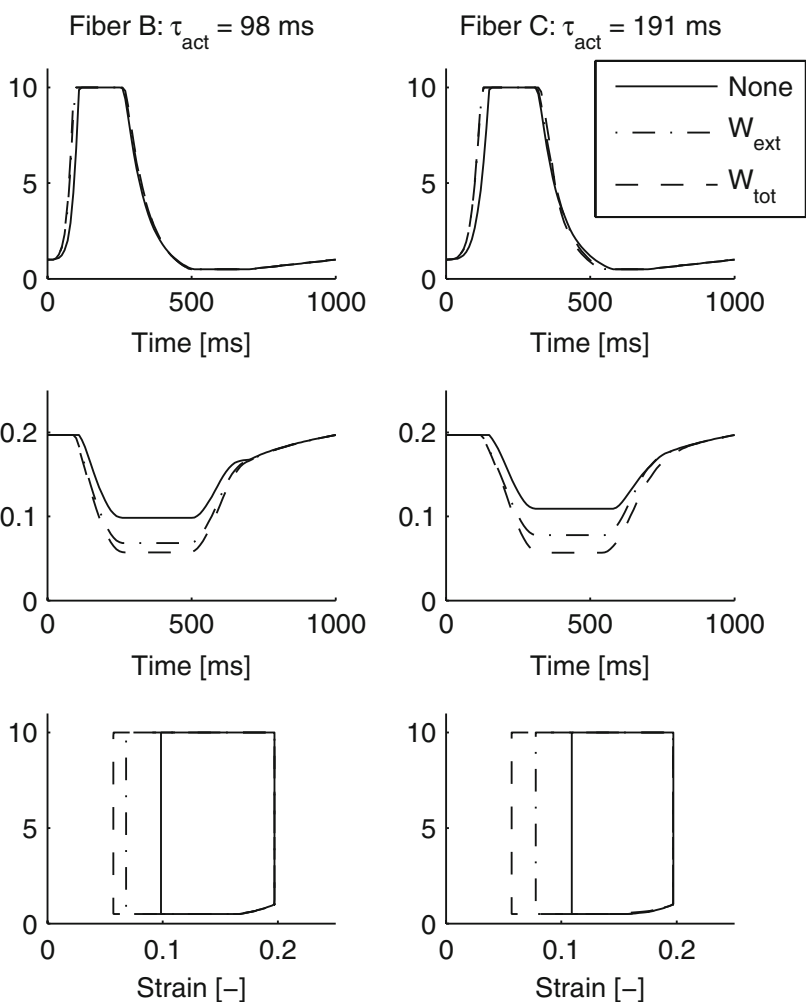

FIGURE 11. Effect of electrical remodeling of $I_{\mathrm{Ca}, \mathrm{L}}$ controlled by $W_{\text {ext }}$ and $W_{\text {tot }}$ on the stress-strain loop for Fibers A, B, and C $\left(T_{\text {rest }}=0.5 \mathrm{kPa}, T_{\text {preload }}=1 \mathrm{kPa}\right.$, and $\left.T_{\text {afterload }}=10 \mathrm{kPa}\right)$. A stimulus current was applied to the segment at $0.0 \mathrm{~cm}$ at $0 \mathrm{~ms}$. $\tau_{\text {act }}$ indicates time of complete activation of the fiber.

with remodeling, such that both onset and relaxation of segment shortening were in agreement with the experimental results of Ashikaga et al. ${ }^{4}$ Thus, cardiomechanics in the ventricles during normal sinus rhythm or RA pacing is better approximated by our model with electrical remodeling of $I_{\mathrm{Ca}, \mathrm{L}}$. We conclude that adaptation of electrophysiology as proposed here may lead to better predictions of ventricular mechanics in coupled models of cardiac electromechanics.

\section{Model Validity and Limitations}

To our knowledge, the model presented here is the first model in which adaptation of electrophysiology is triggered by heterogeneity in mechanical work. Validity and limitations of the models for the ionic currents, cross-bridge formation, and cardiomechanics are extensively discussed elsewhere. ${ }^{12,35,54,61}$ Here, we discuss the validity and limitations of our choices for the cardiac fiber model, the ionic membrane currents, the $\mathrm{Ca}^{2+}$-force relation, the cardiac cycle, and electrical remodeling.

\section{Cardiac Fiber Model}

In the present study, a three-dimensional heart is represented by a single fiber. Regarding cardiomechanics, a basic assumption in our fiber model is that the stress applied to each segment is equal at all times during the cardiac cycle. In the real heart, this is related to the assumption that local stress in the direction of the myofibers is uniformly distributed. It is thus assumed that myofiber orientation in the normal heart is adapted such that myofiber stress and strain are about uniform, which is a valid assumption for the normal heart. ${ }^{3}$ Regarding electrophysiology, our fiber model assumes a uniform distribution of excitation times along the fiber. In the three-dimensional heart this assumption does not hold. Despite this deviation, we found relations between excitation and mechanics that are comparable with the modeling results of Kerckhoffs et al. ${ }^{29,30}$ and the experimental results of Prinzen et al. ${ }^{51}$

\section{Ionic Membrane Currents}

To describe the membrane currents and calcium handling, we apply the Courtemanche-Ramirez-Nattel model of the human atrial action potential. ${ }^{12}$ In this model, calcium handling is based on the ventricular model by Luo and Rudy. ${ }^{44,45}$ The formulation of $\mathrm{Ca}^{2+}$ release from the SR reflects the close coupling of L-type $\mathrm{Ca}^{2+}$ channels and SR $\mathrm{Ca}^{2+}$ release channels. In addition, the formulation is completely analytic and does not require the identification of some trigger event 
(see Courtemanche et al. ${ }^{12}$ for details). Since the model is capable of reproducing the complex interaction between $I_{\mathrm{to}}$ and $I_{\mathrm{Ca}, \mathrm{L}}$ as described by Greenstein et al. ${ }^{18}$ for ventricular models, we conclude that the model is representative for cardiomyocytes in general. By adjusting $I_{\mathrm{Ca}, \mathrm{L}}$ gating variable $d$, our model is capable of reproducing a larger $I_{\mathrm{Ca}, \mathrm{L}}$ current and slower decrease of $I_{\mathrm{Ca}, \mathrm{L}}$ during the plateau phase, which results in an increased APD and plateau height and is in agreement with the experimental results of Plotnikov et $a l .{ }^{49}$ Although we obtain qualitative agreement, fitting $I_{\mathrm{Ca}, \mathrm{L}}$ kinetics to the data provided by Plotnikov et al. ${ }^{49}$ may require a recent ventricular model such as the Winslow-Rice-Jafri model of the canine ventricle ${ }^{71}$ (including the new formulation of $I_{\mathrm{to} 1}$ by Greenstein et $a l .{ }^{18}$ ) or the model by Ten Tusscher et al. ${ }^{66}$

\section{$\mathrm{Ca}^{2+}-$ Force Relation}

Cardiac electromechanical behavior in our model is described by combining the models of Courtemanche et al. ${ }^{12}$ and Rice et al. ${ }^{53,54}$ To model the $\mathrm{Ca}^{2+}$-force relation, we apply model 4 of Rice et al., ${ }^{53,54}$ which approximates the contractile force measured during isosarcometric twitches from RV rat trabeculae. ${ }^{25} \mathrm{In}$ model 4, the affinity of troponin for $\mathrm{Ca}^{2+}$ does not increase in the presence of strongly bound cross bridges. Incorporation of the crossbridge-troponin cooperativity mechanism ${ }^{1}$ as in model 5 would lead to an increasing steepness in the $\mathrm{Ca}^{2+}$-force relation, especially in the midlevel ranges of force. ${ }^{54} \mathrm{In}$ our model, the increased intracellular $\mathrm{Ca}^{2+}$ concentration in early-activated segments would have a more prominent effect on $F_{\text {norm }}$, which leads to a more homogeneous distribution of work.

The choice between model 4 and model 5 is motivated by the fact that we found better agreement between the $\mathrm{Ca}^{2+}$-force relation obtained by model 4 and the experimental results of Kentish et al. ${ }^{28}$ in particular for sarcomere lengths above $1.9 \mu \mathrm{m}$. When we compared the isosarcometric twitches, we found that, for model 5, the peak force was lower and the latency to peak force was increased for longer sarcomeres. Compared with the experimental data measured by Janssen and Hunter, ${ }^{25}$ the latency to peak force increased too much with sarcomere length. ${ }^{35}$ Since the twitches obtained by model 4 better resemble the experimental results from Janssen and Hunter, we have chosen model 4 to describe the $\mathrm{Ca}^{2+}$-force relation. Lab et al. ${ }^{38}$ observed in experiments that a decreased mechanical load during shortening leads to an increased $\left[\mathrm{Ca}^{2+}\right]_{i}$ and a longer APD. These observations are acute and are not related to electrical remodeling. Although direct force feedback may result in a more uniform contraction, we do not consider acute mechanoelectric feedback in the present simulation study.

\section{Cardiac Cycle}

In our model, the cardiac cycle is simulated by an extended preload-afterload experiment. Although the work loops obtained with our values for $T_{\text {preload }}$ and $T_{\text {afterload }}$ are in agreement with the work loops used in the experiments by Iribe et al., ${ }^{24}$ our value of $T_{\text {afterload }}$ is low compared with the afterload of $35 \mathrm{kPa}$ computed by Kerckhoffs et al. ${ }^{30}$ when simulating ventricular work loops. We decided not to increase $T_{\text {afterload, }}$, because that would lead to too little shortening for $\rho=0.0$ (Fig. 5).

\section{Electrical Remodeling}

Electrical remodeling is simulated by changing $I_{\mathrm{Ca}, \mathrm{L}}$ kinetics based on the experiments by Plotnikov et al. ${ }^{49}$ With respect to electrophysiology, our model predicts changes in AP morphology and duration similar to the changes observed after ventricular pacing. ${ }^{11,26} \mathrm{~A}$ less prominent notch of the AP as observed in experiments ${ }^{41,72}$ would occur if not only $I_{\mathrm{Ca}, \mathrm{L}}$ kinetics were adapted, but also $I_{\text {to }}$ conductance was reduced. In addition to $I_{\mathrm{Ca}, \mathrm{L}}$ and $I_{\mathrm{to}}$, transmural heterogeneity was found in $I_{\mathrm{Ks}}{ }^{43}$ and in $I_{\mathrm{NaCa}}{ }^{73}$ Obreztchikova et al. ${ }^{47}$ observed remodeling of $I_{\mathrm{Kr}}$ and $I_{\mathrm{Ks}}$ after three weeks of epicardial pacing. Although these currents influence AP morphology and excitation-contraction coupling, we do not consider remodeling of $I_{\mathrm{Kr}}, I_{\mathrm{Ks}}$, and $I_{\mathrm{NaCa}}$ in our model.

With respect to cardiomechanics, our model predicts homogeneous shortening and mechanical work in the normal heart (represented by Fiber A) when $I_{\mathrm{Ca}, \mathrm{L}}$ is adapted. The homogeneous mechanical behavior is in agreement with experimental observations. ${ }^{13,51}$ Without $I_{\mathrm{Ca}, \mathrm{L}}$ adaptation, the model predicts inhomogeneous shortening and mechanical work during ventricular pacing (represented by Fiber B), which is in agreement with experimental observations after $15 \mathrm{~min}$ of ventricular pacing. ${ }^{13,51}$ With $I_{\mathrm{Ca}, \mathrm{L}}$ adaptation, our model predicts large differences in strain during ejection between early and later-activated segments in Fiber C. These large differences in strain are in agreement with the large differences in peak systolic strains between early and later-activated regions observed by Jeyaraj et $a l^{26}$ after 4 weeks of ventricular pacing.

\section{Clinical Relevance}

Models of cardiac electromechanics have been applied to investigate medical interventions such as cardiac resynchronization therapy (CRT). ${ }^{30,67}$ Extension of models for cardiac electromechanics with 
adaptation of ionic currents in response to changes in mechanical load may lead to more accurate predictions of regional electrical, mechanical, and metabolic properties of cardiac tissue in the healthy heart, during pathology, and during pacing. Application of such models in cardiovascular research may improve our understanding of the interaction between electrophysiology and cardiomechanics.

\section{CONCLUSION}

Experimentally observed heterogeneity in APD and homogeneity in fiber shortening can be reproduced by adaptation of $I_{\mathrm{Ca}, \mathrm{L}}$ kinetics triggered by changes in mechanical work. Thus, adaptation of $I_{\mathrm{Ca}, \mathrm{L}}$ is a possible mechanism to reduce heterogeneity in mechanics induced by heterogeneity in activation.

\section{OPEN ACCESS}

This article is distributed under the terms of the Creative Commons Attribution Noncommercial License which permits any noncommercial use, distribution, and reproduction in any medium, provided the original author(s) and source are credited.

\section{REFERENCES}

\footnotetext{
${ }^{1}$ Allen, D. G., and J. C. Kentish. The cellular basis of the length-tension relation in cardiac muscle. J. Mol. Cell. Cardiol. 17:821-840, 1985.

${ }^{2}$ Allessie, M., J. Ausma, and U. Schotten. Electrical, contractile and structural remodeling during atrial fibrillation. Cardiovasc. Res. 54:230-246, 2002.

${ }^{3}$ Arts, T., P. Bovendeerd, T. Delhaas, and F. W. Prinzen. Modeling the relation between cardiac pump fuction and myofiber mechanics. J. Biomech. 36:731-736, 2003.

${ }^{4}$ Ashikaga, H., B. A. Coppola, B. Hopenfeld, E. S. Leifer, E. R. McVeigh, and J. H. Omens. Transmural dispersion of myofiber mechanics. J. Am. Coll. Cardiol. 49:909-916, 2007. ${ }^{5}$ Bauer, A., R. Becker, C. Karle, K. D. Schreiner, J. C. Senges, F. Voss, P. Kraft, W. Kuebler, and W. Schoels. Effects of the $I_{\mathrm{Kr}}$-blocking agent dofetilide and of the $I_{\mathrm{Ks}^{-}}$blocking agent chromanol $293 \mathrm{~b}$ on regional disparity of left ventricular repolarization in the intact canine heart. J. Cardiovasc. Pharmacol. 39:460-467, 2002.

${ }^{6}$ Bosch, R. F., and S. Nattel. Cellular electrophysioly of atrial fibrillation. Cardiovasc. Res. 54:259-269, 2002.

${ }^{7}$ Brette, F., J. Leroy, J. Y. Le Guennec, and L. Sallé. Ca ${ }^{2+}$ currents in cardiac myocytes: old story, new insights. Progr. Biophys. Mol. Biol. 91:1-82, 2006.

${ }^{8}$ Brutsaert, D. L., and E. H. Sonnenblick. Nature of the force-velocity relation in heart muscle. Cardiovasc. Res. 1(suppl 1):18-33, 1971.
}

${ }^{9}$ Clerc, L. Directional differences of impulse spread in trabecular muscle from mammalian heart. J. Physiol. 255:335-346, 1976.

${ }^{10}$ Cordeiro, J. M., L. Greene, C. Heilmann, D. Antzelevitch, and C. Antzelevitch. Transmural heterogeneity of calcium activity and mechanical function in the canine left ventricle. Am. J. Physiol. Heart Circ. Physiol. 286:H1471-H1479, 2004.

${ }^{11}$ Costard-Jäckle, A., B. Goetsch, M. Antz, and M. R. Franz. Slow and long-lasting modulation of myocardial repolarization produced by ectopic activation in isolated rabbit hearts. Evidence for cardiac "memory". Circulation 80:1412-1420, 1989.

${ }^{12}$ Courtemanche, M., R. J. Ramirez, and S. Nattel. Ionic mechanisms underlying human atrial action potential properties: insights from a mathematical model. Am. J. Physiol. Heart Circ. Physiol. 275:H301-H321, 1998.

${ }^{13}$ Delhaas, T., T. Arts, F. W. Prinzen, and R. S. Reneman. Regional fibre stress-fibre strain area as an estimate of regional blood flow and oxygen demand in the canine heart. J. Physiol. (Lond) 477:481-496, 1994.

${ }^{14}$ Edman, K. A. P. Mechanical deactivation induced by active shortening in isolated muscle fibres of the frog. J. Physiol. 246:255-275, 1975.

${ }^{15}$ Feng, J., L. Yue, Z. Wang, and S. Nattel. Ionic mechanisms of regional action potential heterogeneity in the canine right atrium. Circ. Res. 83:541-551, 1998.

${ }^{16}$ Franz, M. R. Mechano-electrical feedback in ventricular myocardium. Cardiovasc. Res. 32:15-24, 1996.

${ }^{17}$ Franz, M. R., K. Bargheer, W. Rafflenbeul, A. Haverich, and P. R. Lichtlen. Monophasic action potential mapping in human subjects with normal electrocardiograms: direct evidence for the genesis of the T wave. Circulation 75:379386, 1987

${ }^{18}$ Greenstein, J. L., R. Wu, S. Po, G. F. Tomaselli, and R. L. Winslow. Role of the calcium-independent transient outward current $I_{\text {tol } 1}$ in shaping action potential morphology and duration. Circ. Res. 87:1026-1033, 2000.

${ }^{19}$ Henriquez, C. S. Simulating the electrical behavior of cardiac tissue using the bidomain model. Crit. Rev. Biomed. Eng. 21:1-77, 1993.

${ }^{20}$ Herweg, B., F. Chang, P. Chandra, P. Danilo, Jr., and M. R. Rosen. Cardiac memory in canine atrium: identification and implications. Circulation 103:455-461, 2001.

${ }^{21}$ Hill, A. V. The heat of shortening and the dynamic constants in muscle. Proc. Roy. Soc. London 126:136-195, 1938.

${ }^{22} \mathrm{Hu}, \mathrm{H}$., and F. Sachs. Stretch-activated ion channels in the heart. J. Mol. Cell. Cardiol. 29:1511-1523, 1997.

${ }^{23}$ Hunter, P. J., A. D. McCulloch, and H. E. D. J. ter Keurs. Modelling the mechanical properties of cardiac muscle. Progr. Biophys. Mol. Biol. 69:289-331, 1998.

${ }^{24}$ Iribe, G., M. Helmes, and P. Kohl. Force-length relations in isolated intact cardiomyocytes subjected to dynamic changes in mechanical load. Am. J. Physiol. Heart Circ. Physiol. 292:H1487-H1497, 2007.

${ }^{25}$ Janssen, P. M. L., and W. C. Hunter. Force, not sarcomere length, correlates with prolongation of isosarcometric contraction. Am. J. Physiol. Heart Circ. Physiol. 269:H676H685, 1995.

${ }^{26}$ Jeyaraj, D., L. D. Wilson, J. Zhong, C. Flask, J. E. Saffitz, I. Deschênes, X. Yu, and D. S. Rosenbaum. Mechanoelectric feedback as novel mechanism of cardiac electrical remodeling. Circulation 115:3145-3155, 2007.

${ }^{27}$ Kääb, S., B. Nuss, N. Chiamvimonvat, B. O'Rourke, P. H. Pak, D. A. Kass, E. Marban, and G. F. Tomaselli. Ionic 
mechanisms of action potential prolongation in ventricular myocytes from dogs with pacing-induced heart failure. Circ. Res. 78:262-273, 1996.

${ }^{28}$ Kentish, J. C., H. E. D. J. ter Keurs, L. Ricciardi, J. J. J. Bucx, and M. I. M. Noble. Comparison between the sarcomere length-force relations of intact and skinned trabeculae from rat right ventricle. Circ. Res. 58:755-768, 1986.

${ }^{29}$ Kerckhoffs, R. C. P., P. H. M. Bovendeerd, J. C. S. Kotte, F. W. Prinzen, K. Smits, and T. Arts. Homogeneity of cardiac contraction despite physiological asynchrony of depolarization: a model study. Ann. Biomed. Eng. 31:536547, 2003.

${ }^{30}$ Kerckhoffs, R. C. P., O. P. Faris, P. H. M. Bovendeerd, F. W. Prinzen, K. Smits, E. R. McVeigh, and T. Arts. Electromechanics of paced left ventricle simulated by straightforward mathematical model: comparison with experiments. Am. J. Physiol. Heart Circ. Physiol. 289: H1889-H1897, 2005.

${ }^{31}$ Kohl, P., and F. Sachs. Mechanoelectric feedback in cardiac cells. Phil. Trans. R. Soc. Lond. 359:1173-1185, 2001.

${ }^{32}$ Kuijpers, N. H. L., R. H. Keldermann, T. Arts, and P. A. J. Hilbers. Computer simulations of successful defibrillation in decoupled and non-uniform cardiac tissue. Europace 7:S166-S177, 2005.

${ }^{33}$ Kuijpers, N. H. L., R. H. Keldermann, H. M. M. ten Eikelder, T. Arts, and P. A. J. Hilbers. The role of the hyperpolarization-activated inward current $I_{\mathrm{f}}$ in arrhythmogenesis: a computer model study. IEEE Trans. Biomed. Eng. 53:1499-1511, 2006.

${ }^{34}$ Kuijpers, N. H. L., R. J. Rijken, H. M. M. ten Eikelder, and P. A. J. Hilbers. Vulnerability to atrial fibrillation under stretch can be explained by stretch-activated channels. Comput. Cardiol. 34:237-240, 2007.

${ }^{35}$ Kuijpers, N. H. L., H. M. M. ten Eikelder, P. H. M. Bovendeerd, S. Verheule, T. Arts, and P. A. J. Hilbers. Mechanoelectric feedback leads to conduction slowing and block in acutely dilated atria: a modeling study of cardiac electromechanics. Am. J. Physiol. Heart Circ. Physiol. 292:H2832-H2853, 2007.

${ }^{36} \mathrm{Lab}$, M. J. Mechano-electric feedback (transduction) in heart: concepts and implications. Cardiovasc. Res. 32:3-14, 1996.

${ }^{37}$ Lab, M. J. Mechanosensitivity as an integrative system in heart: an audit. Progr. Biophys. Mol. Biol. 71:7-27, 1998.

${ }^{38}$ Lab, M. J., D. G. Allen, and C. H. Orchard. The effects of shortening on myoplasmic calcium concentration and on the action potential in mammalian ventricular muscle. Circ. Res. 55:825-829, 1984.

${ }^{39}$ Laurita, K. R., R. Katra, B. Wible, X. Wan, and M.H. Koo. Transmural heterogeneity of calcium handling in canine. Circ. Res. 92:668-675, 2003.

${ }^{40}$ Libbus, I., and D. S. Rosenbaum. Remodeling of cardiac repolarization: mechanisms and implications of memory. Cardiac Electrophysiol. Rev. 6:302-310, 2002.

${ }^{41}$ Libbus, I., and D. S. Rosenbaum. Transmural action potential changes underlying ventricular electrical remodeling. J. Cardiovasc. Electrophysiol. 14:394-402, 2003.

${ }^{42}$ Libbus, I., X. Wan, and D. S. Rosenbaum. Electrotonic load triggers remodeling of repolarizing current $I_{\text {to }}$ in ventricle. Am. J. Physiol. Heart Circ. Physiol. 286:H1901H1909, 2004.

${ }^{43}$ Liu, D. W., and C. Antzelevitch. Characteristics of the delayed rectifier current $\left(I_{\mathrm{Kr}}\right.$ and $\left.I_{\mathrm{Ks}}\right)$ in canine ventricular epicardial, midmyocardial, and endocardial myocytes: a weaker $I_{\mathrm{Ks}}$ contributes to the longer action potential of the M cell. Circ. Res. 76:351-365, 1995.

${ }^{44}$ Luo, C. H., and Y. Rudy. A dynamic model of the cardiac ventricular action potential. I. Simulations of ionic currents and concentration changes. Circ. Res. 74:1071-1096, 1994.

${ }^{45}$ Luo, C. H., and Y. Rudy. A dynamic model of the cardiac ventricular action potential. II. Afterdepolarizations, triggered activity, and potentiation. Circ. Res. 74:1097-1113, 1994.

${ }^{46}$ Nickerson, D., N. Smith, and P. Hunter. New developments in a strongly coupled cardiac electromechanical model. Europace 7:S118-S127, 2005.

${ }^{47}$ Obreztchikova, M. N., K. W. Patberg, A. N. Plotnikov, N. Ozgen, I. N. Shlapakova, A. V. Rybin, E. A. Sosunov, P. Danilo, Jr., E. P. Anyukhovsky, R. B. Robinson, and M. R. Rosen. $I_{\mathrm{Kr}}$ contributes to the altered ventricular repolarization that determines long-term cardiac memory. Cardiovasc. Res. 71:88-96, 2006.

${ }^{48}$ Patberg, K. W., A. N. Plotnikov, A. Quamina, R. Z. Gainullin, A. Rybin, P. Danilo, Jr., L. S. Sun, and M. R. Rosen. Cardiac memory is associated with decreased levels of the transcriptional factor CREB modulated by angiotensin II and calcium. Circ. Res. 93:472-478, 2003.

${ }^{49}$ Plotnikov, A. N., H. Yu, J. C. Geller, R. Z. Gainullin, P. Chandra, K. W. Patberg, S. Friezema, P. Danilo, Jr., I. S. Cohen, S. J. Feinmark, and M. R. Rosen. Role of L-type calcium channels in pacing-induced short-term and longterm cardiac memory in canine heart. Circulation 107:28442849, 2003.

${ }^{50}$ Prinzen, F. W., C. H. Augustijn, T. Arts, M. A. Allessie, and R. S. Reneman. Redistribution of myocardial fiber strain and blood flow by asynchronous activation. Am. J. Physiol. 259:H300-H308, 1990.

${ }^{51}$ Prinzen, F. W., W. C. Hunter, B. T. Wyman, and E. R. McVeigh. Mapping of regional myocardial strain and work during ventricular pacing: experimental study using magnetic resonance imaging tagging. J. Am. Coll. Cardiol. 33:1735-1742, 1999.

${ }^{52}$ Puwal, S., and B. J. Roth. Forward Euler stability of the bidomain model of cardiac tissue. IEEE Trans. Biomed. Eng. 54:951-953, 2007.

${ }^{53}$ Rice, J. J., M. S. Jafri, and R. L. Winslow. Modeling shortterm interval-force relations in cardiac muscle. $\mathrm{Am}$. J. Physiol. Heart Circ. Physiol. 278:H913-H931, 2000.

${ }^{54}$ Rice, J. J., R. L. Winslow, and W. C. Hunter. Comparison of putative cooperative mechanisms in cardiac muscle: length dependence and dynamic responses. Am. J. Physiol. Heart Circ. Physiol. 276:H1734-H1754, 1999.

${ }^{55}$ Rosenbaum, M. B., H. H. Blanco, M. V. Elizari, J. O. Lazzari, and J. M. Davidenko. Electrotonic modulation of the T wave and cardiac memory. Am. J. Cardiol. 50:213222, 1982.

${ }^{56}$ Rubart, M., J. C. Lopshire, N. S. Fineberg, and D. P. Zipes. Changes in left ventricular repolarization and ion channel currents following a transient rate increase superimposed on bradycardia in anesthetized dogs. J. Cardiovasc. Electrophysiol. 11:652-664, 2000.

${ }^{57}$ Sah, R., R. J. Ramirez, G. Y. Oudit, D. Gidrewicz, M. G. Trivieri, C. Zobel, and P. H. Backx. Regulation of cardiac excitation-contraction coupling by action potential repolarization: role of the transient outward potassium current $\left(I_{\text {to }}\right)$. J. Physiol. 546:5-18, 2003.

${ }^{58}$ Schotten, U., H. R. Neuberger, and M. A. Allessie. The role of atrial dilation in the domestication of atrial fibrillation. Progr. Biophys. Mol. Biol. 82:151-162, 2003. 
${ }^{59}$ Shimizu, A., and O. A. Centurion. Electrophysiological properties of the human atrium in atrial fibrillation. Cardiovasc. Res. 54:302-314, 2002.

${ }^{60}$ Shvilkin, A., P. Danilo, Jr., J. Wang, D. Burkhoff, E. P. Anyukhovsky, E. A. Sosunov, M. Hara, and M. R. Rosen. Evolution and resolution of long-term cardiac memory. Circulation 97:1810-1817, 1998.

${ }^{61}$ Solovyova, O., L. Katsnelson, S. Guriev, L. Nikitina, Y. Protsenko, S. Routkevitch, and V. Markhasin. Mechanical inhomogeneity of myocardium studied in parallel and serial cardiac muscle duplexes: experiments and models. Chaos Soliton Fract. 13:1685-1711, 2002.

${ }^{62}$ Sosunov, E. A., E. P. Anyukhovsky, and M. R. Rosen. Altered ventricular stretch contributes to initiation of cardiac memory. Heart Rhythm 5:106-113, 2008.

${ }^{63}$ Spach, M. S., P. C. Dolber, and P. A. Anderson. Multiple regional differences in cellular properties that regulate repolarization and contraction in the right atrium of adult and newborn dogs. Circ. Res. 65:1594-1611, 1989.

${ }^{64}$ Spach, M. S., P. C. Dolber, and J. F. Heidlage. Interaction of inhomogeneities of repolarization with anisotropic propagation in dog atria: a mechanism for preventing and initiating reentry. Circ. Res. 65:1612-1631, 1989.

${ }^{65}$ Suga, H. Total mechanical energy of a ventricle model and cardiac oxygen consumption. Am. J. Physiol. Heart Circ. Physiol. 236:H498-H505, 1979.

${ }^{66}$ ten Tusscher, K. H. W. J., and A. V. Panfilov. Alternans and spiral breakup in a human ventricular tissue model. Am. J. Physiol. Heart Circ. Physiol. 291:H1088-H1100, 2006.
${ }^{67}$ Usyk, T. P., and A. D. McCulloch. Electromechanical model of cardiac resynchronization in the dilated failing heart with left bundle branch block. J. Electrocardiol. 36:57-61, 2003.

${ }^{68}$ Volders, P. G. A., K. R. Sipido, R. L. H. M. G. Spätjens, H. J. J. Wellens, and M. A. Vos. Repolarizing $\mathrm{K}^{+}$currents $I_{\text {tol }}$ and $I_{\mathrm{Ks}}$ are larger in right than left canine ventricular midmyocardium. Circulation 99:206-210, 1999.

${ }^{69}$ Vollmann, D., Y. Blaauw, H. R. Neuberger, U. Schotten, and M. Allessie. Long-term changes in sequence of atrial activation and refractory periods: no evidence for "atrial memory". Heart Rhythm 2:155-161, 2005.

${ }^{70}$ Wang, H. S., and I. S. Cohen. Calcium channel heterogeneity in canine left ventricular myocytes. J. Physiol. 547:825-833, 2003.

${ }^{71}$ Winslow, R. L., J. J. Rice, M. S. Jafri, E. Marbán, and B. O'Rourke. Mechanisms of altered excitation-contraction coupling in canine tachycardia-induced heart failure, II: model studies. Circ. Res. 84:571-586, 1999.

${ }^{72}$ Yu, H., D. McKinnon, J. E. Dixon, J. Gao, R. Wymore, I. S. Cohen, P. Danilo, Jr., A. Shvilkin, E. P. Anyukhovsky, E. A. Sosunov, M. Hara, and M. R. Rosen. Transient outward current, $I_{\text {tol }}$, is altered in cardiac memory. Circulation 99:1898-1905, 1999.

${ }^{73}$ Zygmunt, A. C., R. J. Goodrow, and C. Antzelevitch. $I_{\mathrm{NaCa}}$ contributes to electrical heterogeneity within the canine ventricle. Am. J. Physiol. Heart Circ. Physiol. 278:H1671H1678, 2000. 